Title: Optimisation of a district energy system with a low temperature network

Author names and affiliations: Ashreeta Prasanna ${ }^{a}$, Viktor Dorer ${ }^{a}$, Nadège Vetterli ${ }^{b}$

${ }^{a}$ Empa, Swiss Federal Laboratories for Materials Science and Technology, Überlandstrasse 129, 8600 Dübendorf, Switzerland

${ }^{\mathrm{b}}$ Lucerne University of Applied Sciences and Arts, Technikumstrasse 21,6048 Horw, Switzerland

Corresponding author: Ashreeta Prasanna

Present/permanent address: ashreeta.prasanna@empa.ch

Empa, Swiss Federal Laboratories for Materials Science and Technology, Überlandstrasse 129, 8600 Dübendorf, Switzerland

This document is the accepted manuscript version of the following article: Prasanna, A., Dorer, V., \& Vetterli, N. (2017). Optimisation of a district energy system with a low temperature network. Energy. http://doi .org/10.1016/j .energy.2017.03.137

This manuscript version is made available under the CC-BY-NC-ND 4.0 1icense http://creativecommons.org/1icenses/by-nc-nd/4.0/ 


\title{
Optimisation of a district energy system with a low temperature network
}

\begin{abstract}
Low temperature district networks (LTNs) supply both low temperature heat and cooling to multiple buildings. Heat input from renewables and waste heat can be fed into LTNs, and they are often connected to long term thermal storage such as borehole fields. LTNs which include new technologies and topologies need to be evaluated in order to enable their further development and application.

The objective of this paper is to evaluate the energy performance of a recently constructed district energy system (DES) with a LTN using a multi-energy network optimisation model. The LTN connects buildings to a borehole field which can be regenerated with heat supply from hybrid solar panels and waste heat from building free-cooling. Monitoring data of heat and free-cooling demand was used as an input to the optimisation model and results were compared with monitoring data of electricity consumption of heat pumps and network pumps. Following validation of the initial model, scenarios with electric storage (batteries) and thermal storage were evaluated. Results from evaluation of scenarios provide insights on how the district energy self-sufficiency can be improved through installation of batteries or by improved use of existing thermal storage.
\end{abstract}

\section{Keywords:}

low temperature district network; mixed integer linear optimisation; pumping electricity; monitoring data; validation 


\section{Nomenclature}

LTN: low temperature district network

DES: district energy system (systems which supply electricity, heating and cooling demand of districts)

DHS: district heating system (heating only)

PV: photovoltaic

PVT: hybrid photovoltaic

BHS: borehole field (ground) storage

MILP: mixed integer linear programming

HP: heat pump

NP: network pump (pump which either draws heat from or sends heat into a network. This could be the pump delivering heat to the HP or the pump linked to the free-cooling circuit.

bi-directional: term used to describe heat fluxes from a network to buildings and from buildings to a network (two directions).

energy hub/network nodes: A unit where multiple energy carriers(electricity, heat, gas, etc) can be converted, conditioned, and stored. In this paper nodes are buildings, borehole entry points, or network routing points.

BF: building sites

COP: coefficient of performance of a heat pump

Multi-energy network optimisation: use of a mathematical optimisation model to represent electricity, heat or gas networks, and their storage and conversion for final end-use.

SOC: state of charge, used in context with electric or heat storage.

SH: space heating

DHW: domestic hot water 


\section{Introduction}

\subsection{Background}

Renewable energy sources such as solar, wind, biomass and geothermal heat, as well as waste or excess heat, are characterised by rather small-scale potentials which are geographically spread. With the increased utilisation of these energy sources, heat in a district heating system (DHS) need not only be supplied by a central plant. Rather, a DHS could have a multitude of heat entry nodes, depending on the geographic location of the various heat sources.

In order to use heat from renewables and waste heat, new concepts for district heating have evolved, with networks which generally operate at temperatures below $30^{\circ} \mathrm{C}$, and which can operate with more than one (decentralised) heat source. These low temperature district networks (LTNs) are also called "Low-Ex" in IEA [1,2], "Cold" in Germany [3] or "Anergy" networks in Switzerland [4,5]. Such networks need not directly supply heating, but rather serve as a low temperature heat source for heat pumps and as a cold source for free-cooling. Certain types of LTNs have a ring configuration and can be extended from existing district heating networks. Due to lower operating temperatures, these networks have lower heat losses and can also be directly connected to borehole fields which play an important role in longterm (seasonal) heat storage.

\subsection{Previous work}

In relation to district heating system design and operation, there are number of models and software tools as well as commercial software products available. These models/tools may also include topological or external optimisation modules. However, most can only be used to model or simulate linear designs, but not ring or mesh topologies, bi-directional flow conditions or multiple heat supply nodes. Thus, additional models need to be developed and existing models and tools need to be adapted in order to design and evaluate more complex heat networks.

Due to the large amount of design and operational parameters to be considered in the design of decentralised district energy systems (DES), optimisation based approaches have proved to be a valuable way to support decision making in the design phase. Most of these approaches include genetic algorithms (GA) or mixed integer linear programming (MILP) for multienergy network optimisation [6,7], or a combination of both [8]. Advanced DES design tools consider part-load plant efficiencies and different types of distribution networks for heating, cooling and electricity [9], or power flow constraints in the electric grid [10]. A number of 
DES optimisation models [9,11-14] include thermal networks. Heat losses in the network are often considered as a fixed percentage of heat transported, as within the DESDOP tool [12] or the EnerGIS model [15] or are pre-calculated [11]. Electricity required for pumping is usually only considered in simulation models and assessments in simplified form $[2,16]$. Ruesch et al. simulated network pumping energy in a LTN and compared their simulation with data from monitoring [17].

Lund et al. in their paper on 4th generation district heat networks define low-temperature networks to have around $50^{\circ} \mathrm{C}$ supply and $20^{\circ} \mathrm{C}$ return (annual average) [18]. While research has found lowering the temperature of district networks decreases cost and improves efficiency $[16,19,20]$, very few performance assessments of DES with LTNs have been documented so far. Brand et al. have simulated the impact of decentralised heat input/output (by prosumers) on a district network. Their results indicate that introduction of prosumers is possible, but requires management and control [21]. Stuebler et al. investigate the advantages and disadvantages of the heat supply of a district with decentralised heat pumps and a cold district heating network which is operated at a temperature level of $10^{\circ} \mathrm{C}$, compared to a central heat pump and traditional district heating network [3]. Their assessment however, does not include (decentralised) thermal inputs into the network in the form of waste heat or solar thermal production.

\subsection{This paper}

This paper analyses a DES with a LTN which operates at temperatures ranging from $8^{\circ} \mathrm{C}$ to $18^{\circ} \mathrm{C}$. In this LTN, heat consumers (buildings) can also be producers and feed heat from different sources (waste heat, renewables) into the network. Consumers therefore become prosumers. A model of the DES using multi-energy network optimisation (energy-hub approach) is implemented, and results are compared with data from a comprehensive monitoring campaign. Optimisation is used to identify if electricity required for pumping can be decreased (by managing heat dispatch into the network). Another aim is to identify if the PV production within the district can cover most of its electricity demand, or if additional storage is required to increase self-use of PV production. New elements in this implementation of the multi-energy optimisation model are: monitoring data used as an input to the model, buildings with bi-directional energy exchange, a borehole field, and consideration of electricity demand for pumping. An optimisation of system operation with fixed capacities and technologies (heat pumps, heat storage) is used to obtain optimal operational profiles and energy flows in the network. Heat losses along pipes are also 
considered, following previous approaches. Few multi-energy optimisation models have been

verified or validated so far. This is because it is difficult to validate DES designs until they are built and their energy performance is monitored. Thus, a first attempt at modelling an existing DES using an optimisation model, and verification and validation of the model through comparison with monitoring data is presented in this paper.

The case study is described in section 2, the methodology in section 3 and the multi-energy optimisation model in section 4 with detailed model equations in appendix A1. Results are presented in section 5 and 6 and discussed in section 7. Finally, conclusions of this modelling work are presented in section 8 .

\section{Case study description}

The case study evaluated in this paper is the Suurstoffi district situated in Risch Rotkreuz, Switzerland. The district consists of low energy commercial and residential buildings (19 buildings considered in this analysis and around 32 total planned, further details in appendix A2, figure A1). For our analysis we considered buildings in site 2 (BF2) which consists of a group of 6 residential buildings, a kindergarten, and a community centre; site 5 (BF5) which consists of a group of mixed use (office and residential buildings); and site 3 (BF3) which consists of a group of 9 residential buildings. The LTN supplying this district with heat and free-cooling connects the buildings with a borehole field ground storage (BHS) consisting of 215 boreholes with $150 \mathrm{~m}$ depth. Construction of the district will be completed in 2020, and the complete network will include an additional BHS with 180 boreholes of $300 \mathrm{~m}$ depth. The model representing the district includes 17 buildings (BF5 considered as one building) and three borehole entry points (only the existing borehole field was included in the model). Heating and domestic hot water for the buildings is produced by decentralised heat pumps (HPs) which are supplied with low temperature heat from the LTN. Waste heat from freecooling is fed into the LTN and subsequently the BHS. Conventional and hybrid photovoltaic panels (PV, PVT) installed on the roofs supply part of the electricity demand of the district and also feed heat into the LTN for the regeneration of the BHS. The DES has seasonal thermal storage, which enables low non-renewable primary energy consumption [1-3]. The installed capacity of PV, borehole fields, and a summary of the heating and cooling demand is described in tables $1 \mathrm{a}, 1 \mathrm{~b}$ and $1 \mathrm{c}$. 
Table 1a. Description of installed PV and PVT capacity in district.

\begin{tabular}{lllll} 
& $\begin{array}{l}\text { Total installed } \\
\text { area }\left[\mathrm{m}^{2}\right]\end{array}$ & $\begin{array}{l}\text { Total installed } \\
\text { capacity }[\mathrm{kWp}]\end{array}$ & $\begin{array}{l}\text { Electricity } \\
\text { production } \\
{[\mathrm{kWh} \text { per year }]}\end{array}$ & $\begin{array}{l}\text { Thermal } \\
\text { production } \\
{[\mathrm{kWh} \text { per year }]}\end{array}$ \\
\hline $\begin{array}{l}\text { PV panels } \\
\text { [data from monitoring, }\end{array}$ & 3484 & 595 & 345 & 0 \\
$\begin{array}{l}\text { BF2+BF5] } \\
\text { PVT panels [BF3, simulation] }\end{array}$ & 2704 & 424 & & \\
\hline Total & 6188 & 1019 & 401 & 1367 \\
\hline
\end{tabular}

Table 1b. Summary of district heating and cooling demands (expanded table in appendix A2, table A2).

\begin{tabular}{llllll} 
& $\begin{array}{l}\text { Space heating } \\
{[\mathrm{MWh} / \mathrm{y}]}\end{array}$ & $\begin{array}{l}\text { Hot water } \\
{[\mathrm{MWh} / \mathrm{y}]}\end{array}$ & $\begin{array}{l}\text { Cooling } \\
{[\mathrm{MWh} / \mathrm{y}]}\end{array}$ & $\begin{array}{l}\text { Total heating } \\
{[\mathrm{MWh} / \mathrm{y}]}\end{array}$ & $\begin{array}{l}\text { Total Cooling } \\
{[\mathrm{MWh} / \mathrm{y}]}\end{array}$ \\
\hline BF2 & 629 & 283 & 56 & 912 & 56 \\
BF5 & 797 & 380 & 533 & 1177 & 533 \\
BF2+BF5 [measured] & 1426 & 663 & 589 & 2089 & 589 \\
BF3 & 507 & 213 & 64 & 720 & 64 \\
BF2+BF5+BF3 & 1933 & 876 & 653 & 2809 & 653 \\
\hline Whole site [estimate] & 5624 & 1828 & 2117 & 7452 & 2117
\end{tabular}

Table 1c. Summary of borehole fields.

\begin{tabular}{llll} 
& Number of boreholes & Depth $[\mathrm{m}]$ & Capacity $[\mathrm{GW}]$ \\
\hline Borehole field 1 & 220 & 150 & 2 \\
Borehole field 2 [in construction] & 180 & 300 & 3
\end{tabular}

\subsection{Monitoring}

The Suurstoffi DES is monitored in order to provide insight on its operational and technical efficiency, the behaviour of the thermal storage system, functionality of building technologies (including the view of users), as well as thermal comfort. Monitoring data includes demand for heating and domestic hot water, cooling, electricity of HPs and network pumps in BF2 and BF5, and temperature at borehole entry and exit points. The monitoring data used in this paper refer to those measured from 1 October 2013 to 30 September 2014 and the annual demand curves are shown in figure A2 in appendix A2. The Lucerne University of Applied 
Sciences, Switzerland, has analysed monitoring data from 2012 till 2016 [4,22-24]. Their analysis found heat demand is on average $50 \%$ higher than the nominal heat demand used for the planning and dimensioning of the district. Demand for cooling is also much lower than the nominal design values for planning. The difference between predicted heating and cooling demand and actual demand (monitored) has a significant impact on LTN operation and the energy balance of the BHS $[25,26]$.

\section{Methodology}

Figure 1, which is a diagram adapted from [27], provides an overview of the modelling methodology. A model describing the DES and LTN was implemented using a multi-energy network optimisation or energy-hub approach $[6,7,28]$. The model was initially run with monitoring data of heating, domestic hot water, and free-cooling demand for buildings in BF2 and BF5 (initial case). It was then validated by comparing results of electricity consumption of HPs and network pumps with the respective data from monitoring. The electrical production of the PV panels, and the heat delivered to HPs from the LTN were also compared to complete the validation of the model describing BF2 and BF5. Additional buildings of construction site 3 (BF3) were then included in the validated model and together with BF2 and BF5 represent the base case. Since no data was available for BF3, the heating and cooling demands of buildings in BF3 were based on the monitored demand profiles of buildings in BF2 (BF3 has similar sized residential buildings as BF2). Scenarios considering additional electrical and thermal storage were subsequently evaluated. 


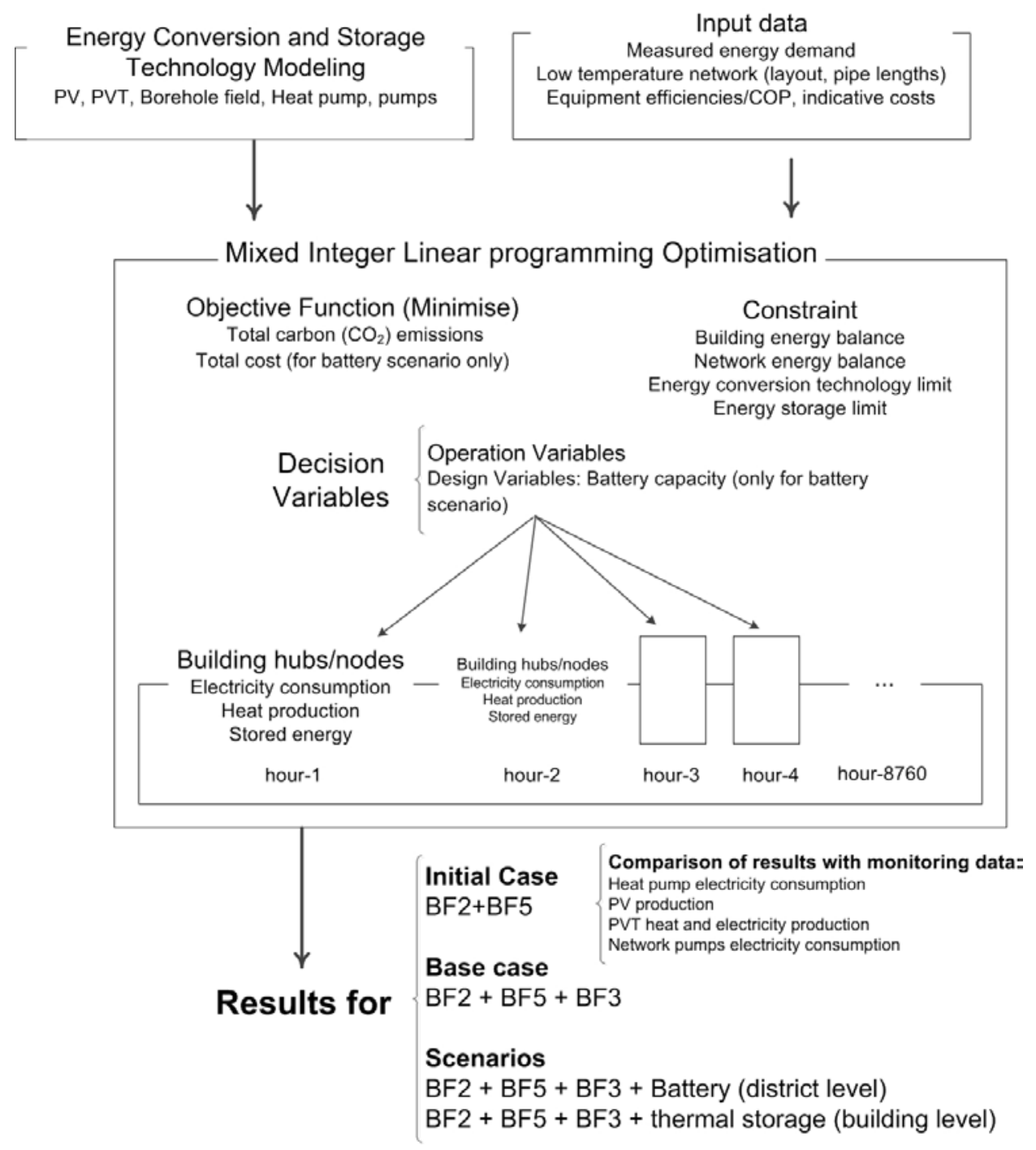

Figure 1. Description of modelling methodology.

\section{Description of the optimisation model and boundary conditions}

The DES was formulated as a mixed-integer linear programming problem (MILP). The mathematical description of subsystems is based on earlier work by Morvaj et al. [14]. A MILP consists of linear equations with parameters (inputs varying over time or fixed value), variables, and constraints based on system requirements and energy balance at each LTN node and each time step. An objective function, minimisation of total carbon emissions (described in section 4.1) was defined. The model was implemented in AIMMS, a software tool for optimisation modelling using the solver IBM CPLEX. The CPLEX solver finds the optimum solution for the objective function, subject to defined constraints.

A detailed description of the technology components and related constraints is provided in appendix A1. The base case model consists of 30 nodes or energy hubs (figure 2 appendix 
A2). Of these, 17 nodes represent buildings, 3 represent the borehole field entry points, and 11 represent points in the network where it branches, mainly included to represent accurate energy routing in the LTN.

The building model is described in figure 2 while the network model in figure 3 and figure A2 in appendix A2. Each building was modelled with the same configuration; a two stage HP to supply space heating and domestic hot water demands (equations 6-8 in appendix A1), PV or PVT panels (equations 1-5 in appendix A1) and a network pump (equations 15-21 in appendix A1). Buildings in BF2 and BF5 were modelled with photovoltaic (PV) panels while those in BF3 were modelled with PVT panels, following the real case. The borehole field was modelled as heat storage, with a storage model located at each of the 3 borehole field entry points (equations 9-14 in appendix A1). Routing nodes were modelled as nodes at which an energy balance occurred, but no energy conversion nor storage (equation 24 in appendix A1). All technologies were modelled with fixed or time step dependent efficiencies and fixed coefficient of performance (COP). The equipment capacities and assumed efficiencies are listed in table A1 in the appendix A2.

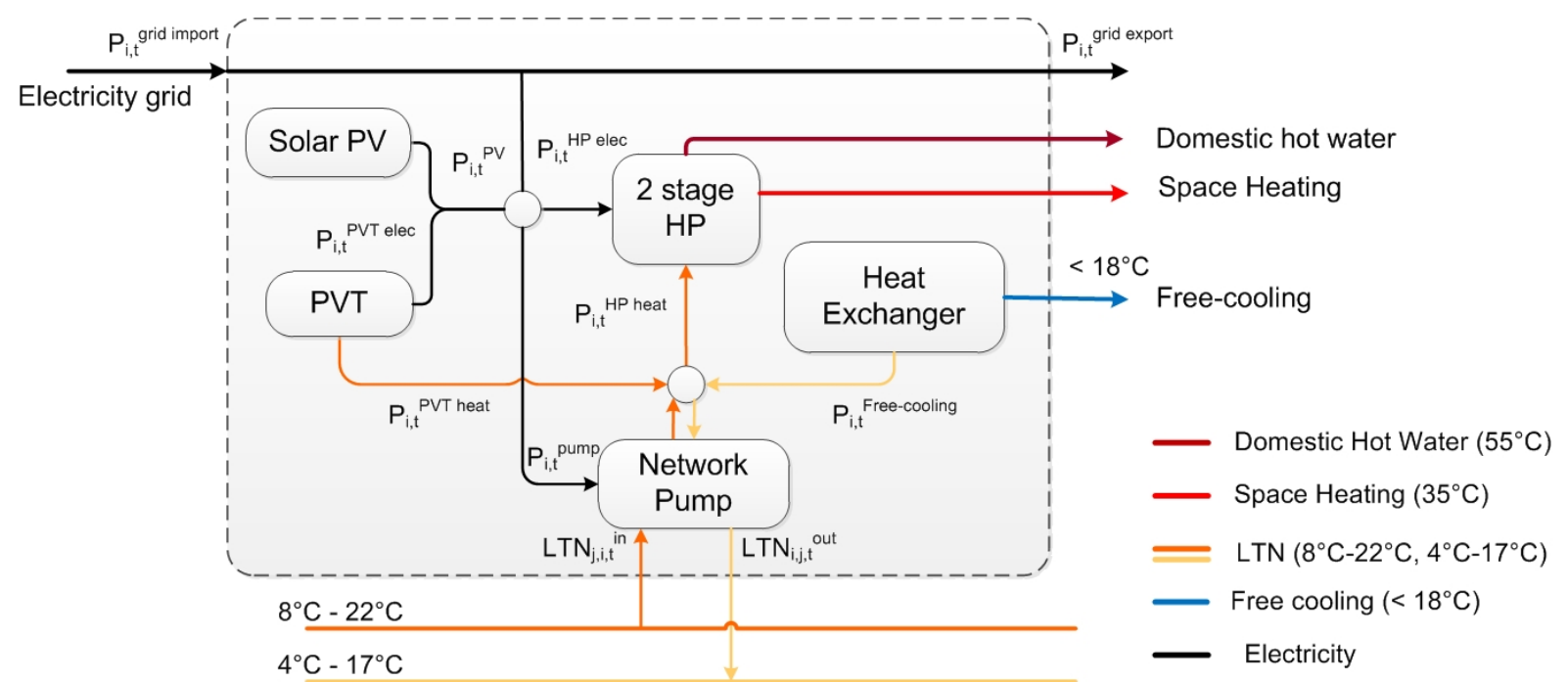

Figure 2. Components included within the building energy hub model. 


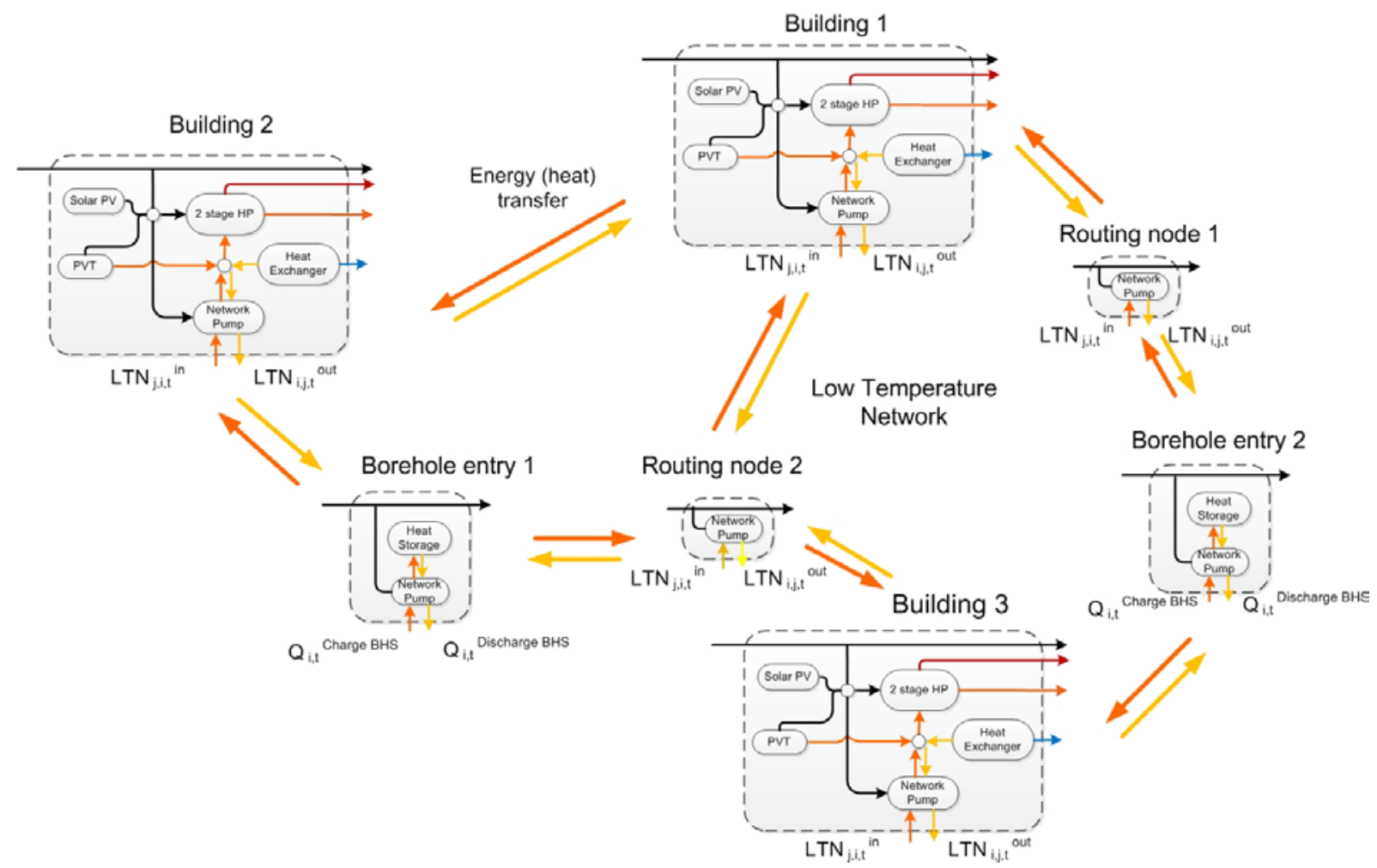

Figure 3. Components included within the network model. Only part of the network is represented here; the base case model includes 17 buildings nodes, 3 borehole entry nodes and 11 routing nodes. Details of the sub-model for building nodes is shown in figure 2.

The LTN was modelled with accurate pipe lengths and three entry points to the BHS (appendix A2, figure 2 and equations 22 and 23 in appendix A1). Electricity demand for pumping was calculated as a function of heat transferred through the LTN and pipe length between nodes (appendix A1, equations 17-21). Thermal losses were calculated as a percentage of heat transferred though pipes (appendix A1, equation 23). The maximum charge and discharge rate of the BHS in this district is limited by the flow rate $\left(1.8 \mathrm{~m}^{3} / \mathrm{h}\right)$. This was considered in the model by imposing constraints for the maximum charge and discharge rate (appendix A1, equation 11 and 12). All network interactions were modelled as linear functions. Dynamic interactions between LTN temperature and mass flow were not considered within this model since they require non-linear representations which cannot be described within the current framework. The energy balance equations of the network are described in appendix A1 (equations 25 to 28, appendix A1). 
The MILP was solved for an objective function to obtain results for all variables for each time step (hourly). Minimisation of total annual carbon emissions was used as an objective function. Since the district is entirely electricity based, the total carbon emissions are equal to the amount of electricity purchased from the grid $\left(P_{i, t}^{\text {grid import }}\right)$ multiplied by its carbon factor $\left(C F_{\text {grid }}\right)$ (equation 1, see also appendix A1, equation 32$)$. The electricity produced by the PVT/PV on site was assumed to have zero carbon emissions. The surplus of electricity delivered to the grid was assumed to have no positive effect on the grid carbon factor.

Carbon $_{\text {total }}=\sum_{i} \sum_{t}\left(C F_{\text {grid }} * P_{i, t}^{\text {grid import }}\right)$

For the initial and base case, optimisation of system operation was carried out. Design optimisation and selection of equipment capacity was not necessary since the DES is already built. For scenarios, both design optimisation (choice of battery capacity) as well as system operation optimisation was carried out. Since the objective function of carbon minimisation requires minimising the import of grid electricity, all variables contributing to total electricity consumption were decision variables. These were: operation of HPs, operation of network pumps, amount of PV and PVT electricity sold and used on site, charge and discharge of the BHS, and heat transferred though the LTN between nodes and the directionality of this heat transfer.

\section{Results of model and validation}

Results for LTN operation were obtained for 8760 hours. Model results from optimisation with an objective function of carbon minimisation were compared with data from monitoring for the initial case (BF2 and BF5) and are shown in figure 4a and 4b. Figure 4a compares HP and NP electricity consumption, and PV or PVT production of the two BFs with their respective monitoring data. The energy balance in the LTN is compared in figure $4 \mathrm{~b}$. This is calculated as the heat fed into the LTN (and subsequently the BHS) subtracted by the heat input from the LTN to the buildings. 


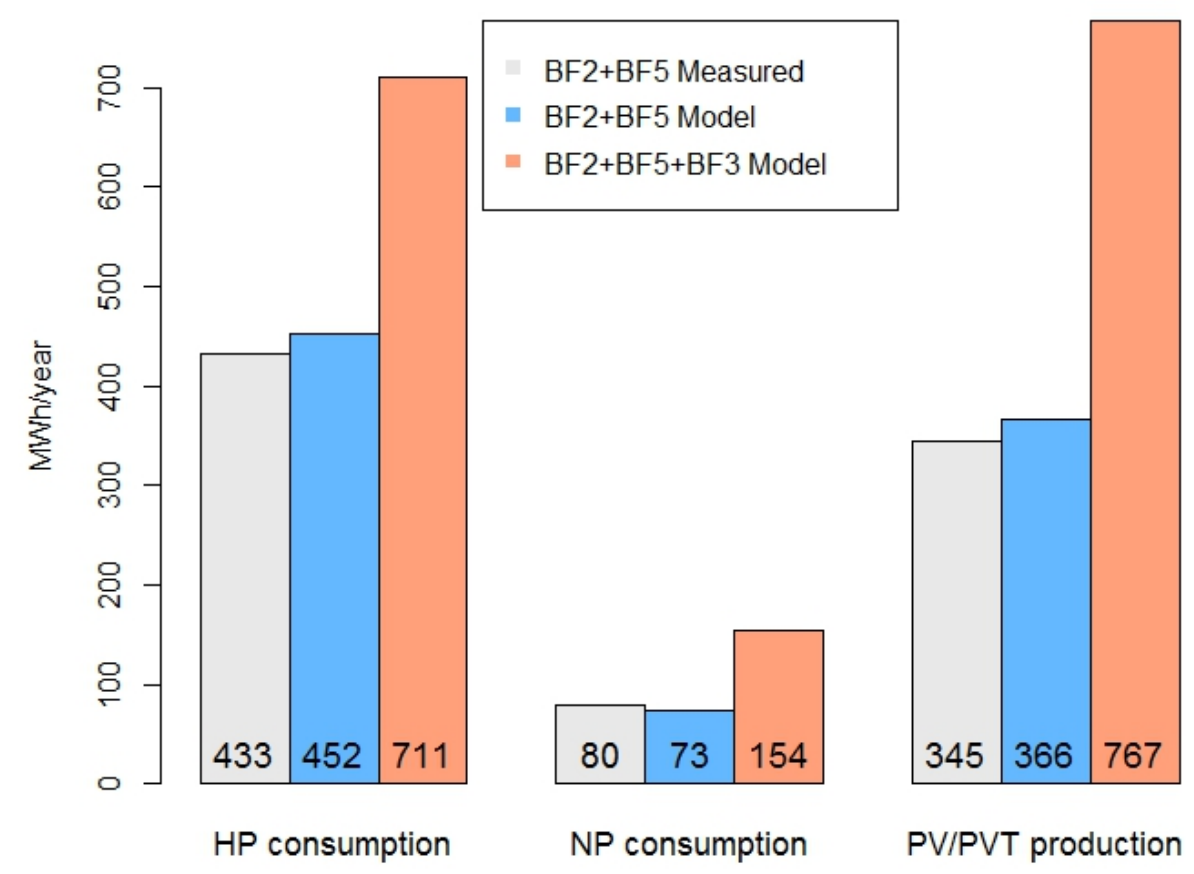

Figure 4a. Results of model for the initial case $(B F 2+B F 5)$ and the base case $(B F 2+B F 5+B F 3)$ compared with data from monitoring.

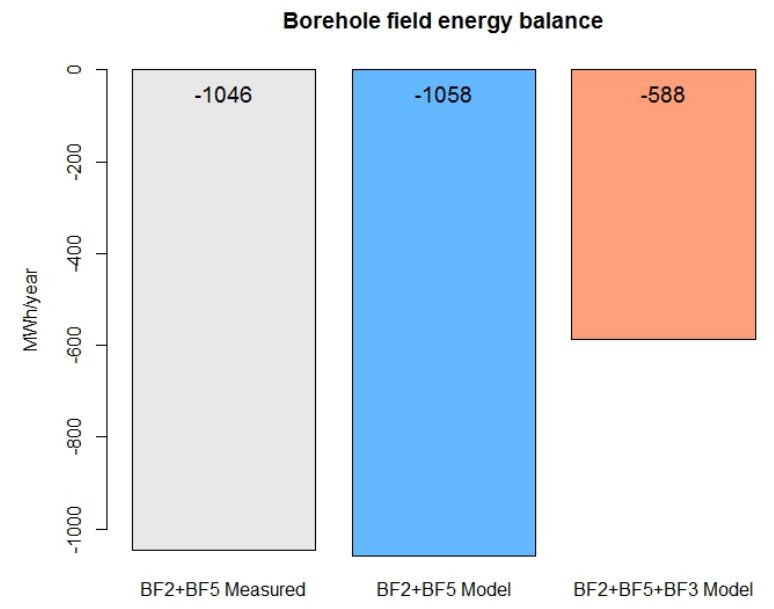

Figure 4b. Model result of borehole field energy balance for the initial case $(B F 2+B F 5)$ and the base case $(B F 2+B F 5+B F 3)$ compared with data from monitoring.

The difference in annual PV production between measurements and model results is $6 \%$ while the difference between measurements and model results for NPs and HPs is $8 \%$ and $4 \%$ 
respectively (figure 4a). The difference between measurements and model for energy balance in the LTN is $1 \%$ (figure $4 b$ ).

For the base case with $\mathrm{BF} 2, \mathrm{BF} 5$ and $\mathrm{BF} 3$, the estimated additional PV production, HP consumption and network pump consumption is shown in figure $4 a$. In figure $4 b$, the results for the base case energy balance in the LTN is improved when compared to the initial case due to the additional heat supply from PVT panels. This result takes into account the reduced performance of PVT panels during summer months with a time varying efficiency factor. However, the model does not consider limitation on the temperature of heat supply into the LTN. The only limitation considered on heat supply from PVT into the LTN is the maximum charging rate of the borehole field. Thus, the result for the base case is an optimistic estimate of the energy balance in the LTN.

\subsection{Comparison of monitoring data of BF2 PV production with model results}

The PV production of buildings in BF2 is compared with model results (hourly time steps) in figure 5. In the model a radiation profile for the region is used as an input with a fixed efficiency factor (appendix A1, equation 1). Since actual PV production can vary based on other factors such as clouds and other weather conditions, there are differences observed in measured profiles and profiles produced by the model. Figure 5 (top) shows hourly monitoring data compared with the hourly model results for PV production of panels in BF2. Figure 5 (middle) shows the comparison of the profile for 7 selected days. Both figures show that hourly PV production could be underestimated or overestimated during different time periods.

235 Figure 5 (bottom) shows a comparison of the box plot of monitoring data with the box plot of model results for each month. The lower and upper hinges of each box correspond to the first and third quartiles (the 25th and 75th percentiles). The line inside each box marks the median (hourly production) and the whiskers extend till the maximum and minimum (hourly production) for each month. Data beyond the end of the whiskers are called "outlying" points and are plotted individually. The median hourly PV production closely matches the monitored data. 
PV BF2 production annual profile

- PV BF2 Measured - PV BF2 Model

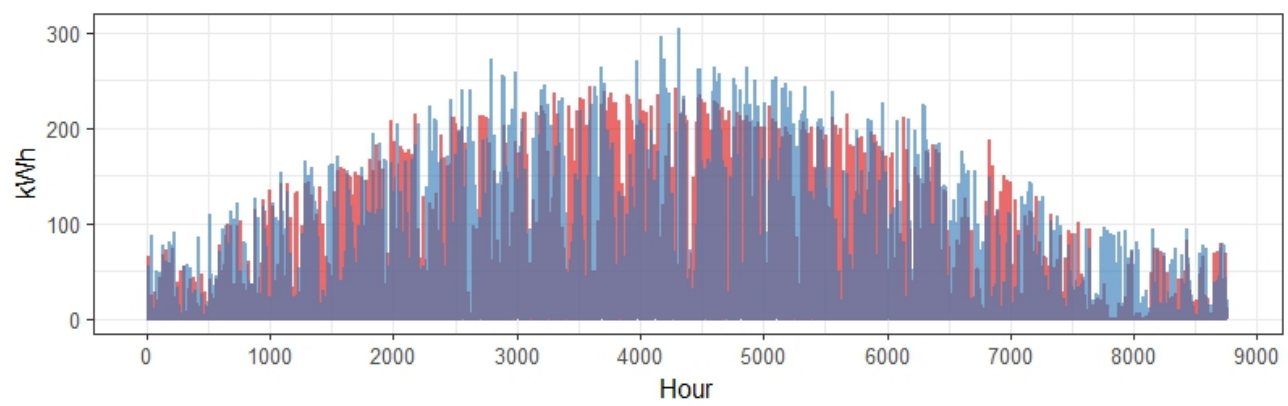

PV BF2 production 7 selected summer days profile (hour 4873 to 5040 )

- PV BF2 Measured - PV BF2 Model

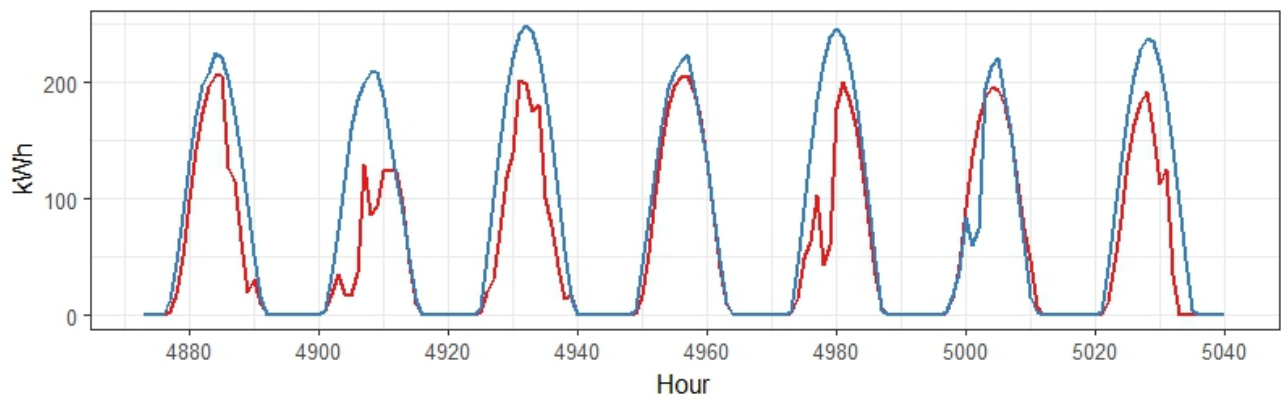

PV BF2 median hourly electricity production for each month

由PV BF2 Measured 官PV BF2 Model

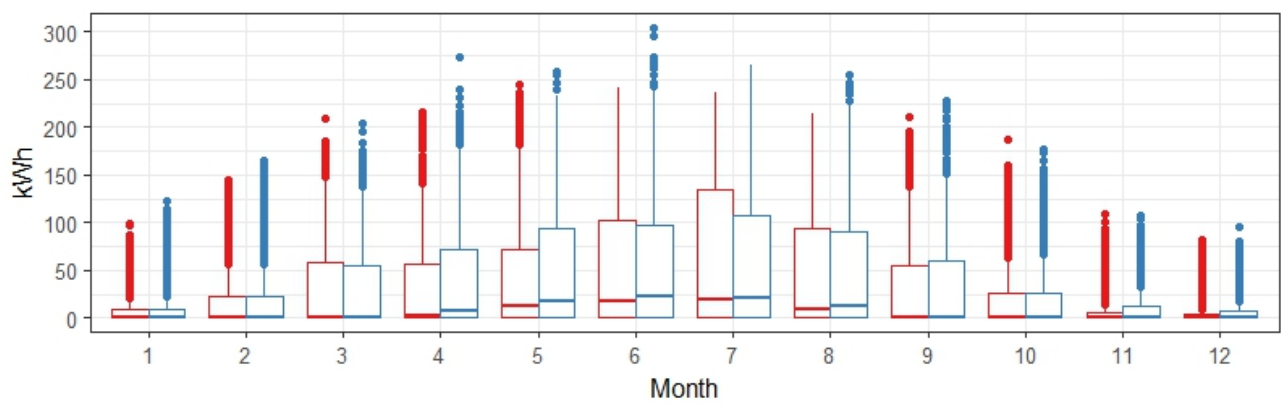

Figure 5. Monitoring data of BF2 PV production (red) compared with model results (blue).

\subsection{Comparison of monitoring data of HP in BF5 with model results}

The annual HP electricity consumption of buildings in BF5 is compared with model results in figure 6. The model uses a fixed average COP for the HP in each building, and thus assumes a constant inlet and outlet temperature for the HP (equations 6 to 8 in appendix A1). Although the linear approximation results in differences between monitored data and model results, it provides a good estimate of HP consumption (figure 6). In figure 6 (top) the hourly monitoring data of HP electricity consumption during summer months is higher than model results. During summer the two stage heat pump in BF5 operates at part load, because it delivers only domestic hot water and no space heating. The model considers a fixed COP for 
all months, while the actual COP varies according to the operating conditions of the HP. Thus the HP in BF5 has a lower COP for summer months due to part-load operation.

255 In figure 6 (bottom) a comparison of the box plot of monitored data with the box plot of model results for each month is shown. In figure 7 the monitored heat intake is compared with model results. Similarly, there are differences in the profiles but the model provides a reasonable estimate of the monthly heat intake.

HP BF5 electricity consumption annual profile

- HP BF5 Measured - HP BF5 Model

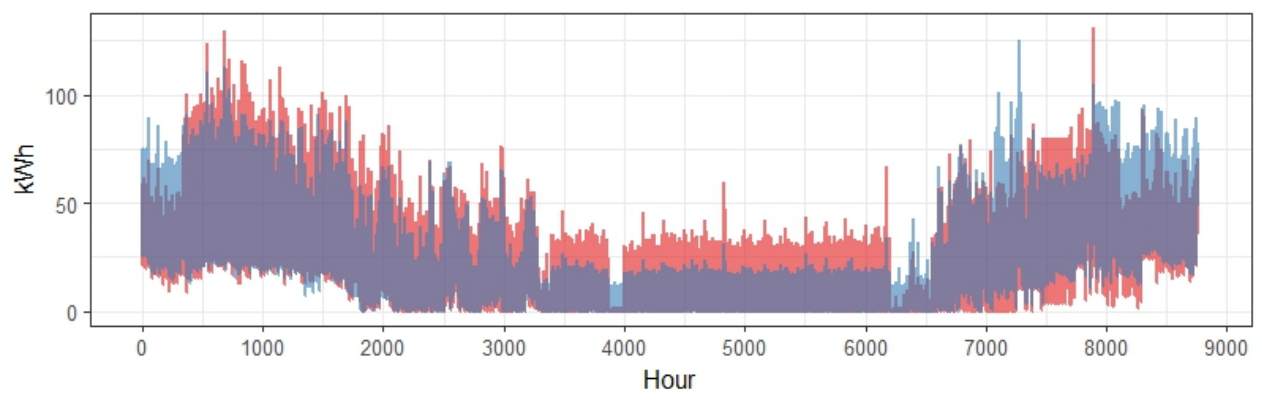

HP BF5 electricity consumption 8 selected days profile (hour 2378 to 2569 )

- HP BF5 Measured - HP BF5 Model

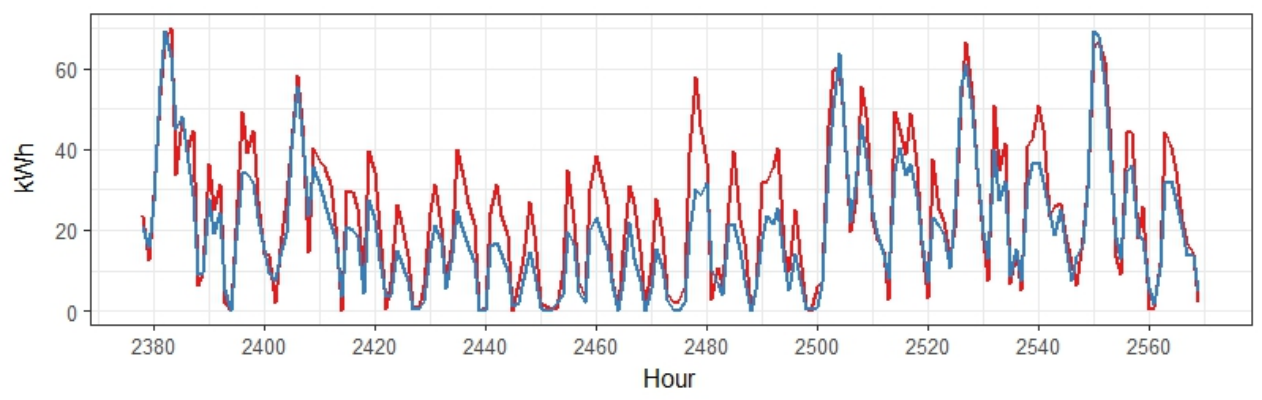

HP BF5 median hourly electricity consumption for each month

追HP BF5 Measured

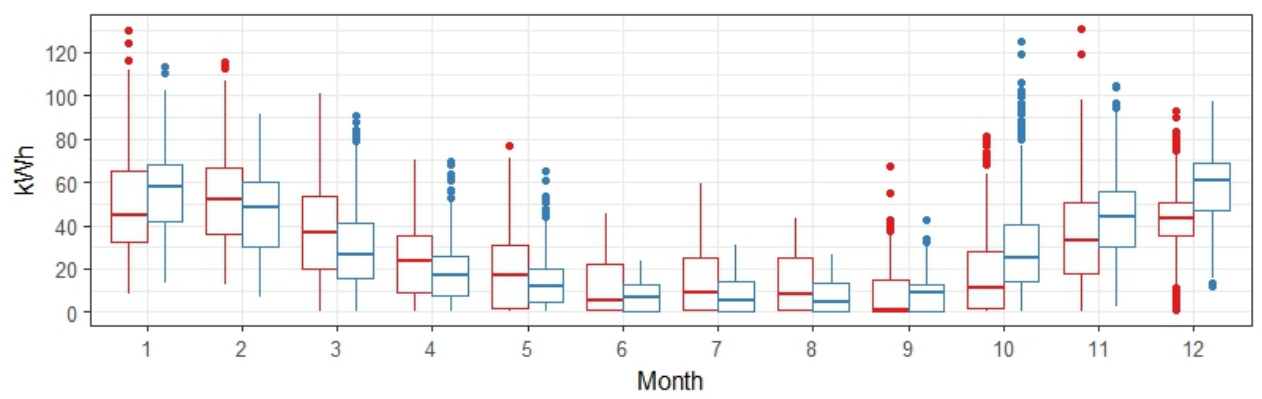

Figure 6. Monitoring data of BF5 HP electricity consumption (red) compared with model results (blue). 
HP BF5 heat intake from LTN annual profile

- HP BF5 heat intake Measured - HP BF5 heat intake Model

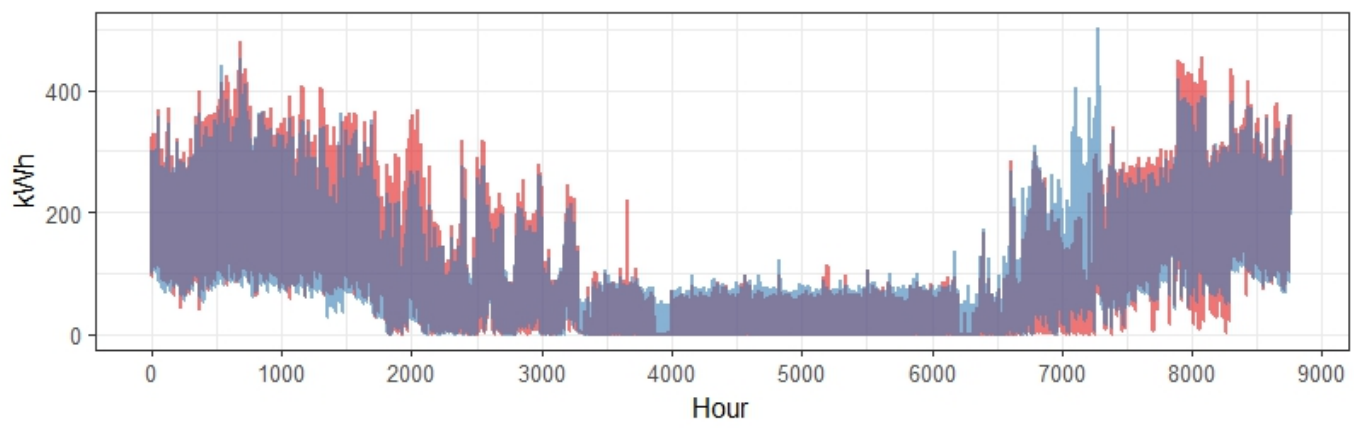

HP BF5 heat intake from LTN 8 selected days profile (hour 2378 to 2569 )

- HP BF5 heat intake Measured - HP BF5 heat intake Model

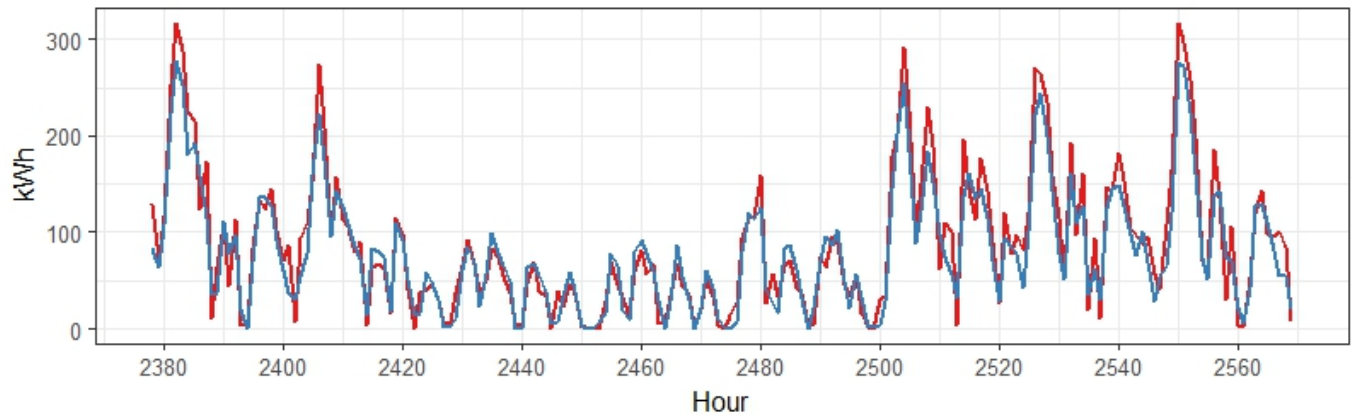

HP BF5 median hourly heat intake for each month

穴 HP BF5 heat intake Measured $\boxminus$ HP BF5 heat intake Model

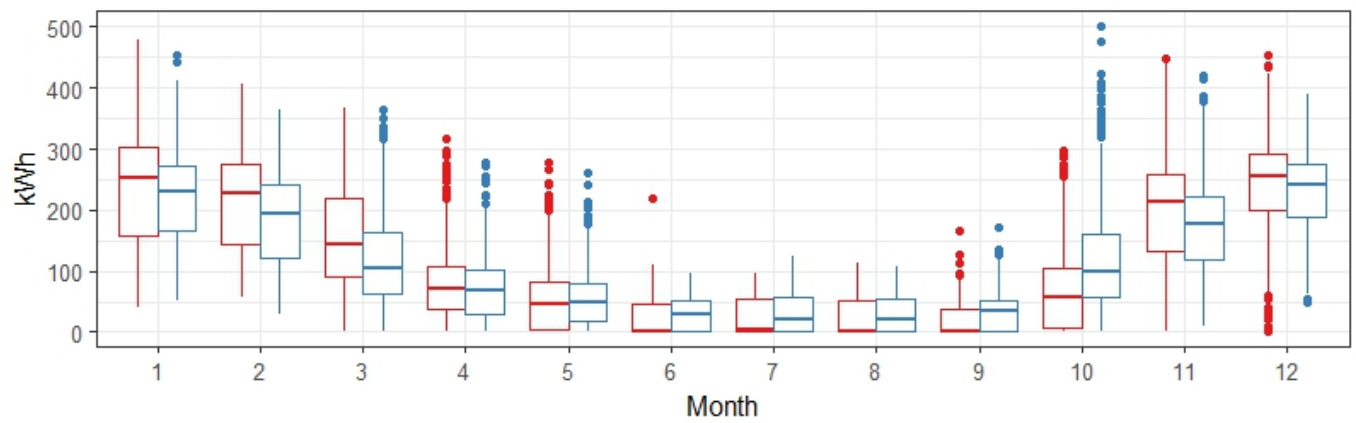

Figure 7. Monitoring data of BF5 HP heat intake (red) compared with model results (blue).

5.3. Comparison of monitoring data of electricity consumption of network pumps with model results

The hourly monitored NP electricity consumption is compared with model results in figure 8 . Certain assumptions are made in the model, for example the model assumes a pump at each of the borehole entry points as well as at the routing nodes; while in reality pumps are only present in buildings (equation 17, appendix A1). The model also assumes a single pump at each node, while in reality the pumping systems to deliver heat to HPs and supply freecooling within buildings are separate. Finally, the model assumes a constant temperature 
difference between the warm and cold pipes of the LTN (delta T) throughout the year. In figure 8 (top) the profile of LTN temperature measured at a borehole entry point is shown. The temperature difference is lower during summer months and higher during winter months which directly impacts NP consumption: as explained in appendix A1, the pumping energy is inversely related to the temperature difference. These assumptions lead to differences between monitored data and model results of NP consumption, especially during summer months. While the model results of NP consumption match the monitoring data during winter (figure 8 , bottom), there are significant differences in the operation profile during summer (figure 8 , top). The modelled NP results have an on-off operation (related to the cooling demand which is not constant), while in reality, the network pumps operate continuously at certain set-points (appendix A2, figure A4).

A modification to the model was made in order to better represent the real case and it was redefined considering network pumps only at building nodes (equations 19 to 21, appendix A1). The results of this modified model are able to better follow the monitored data profile as seen in figure 9. For the modified model, all other results such as HP consumption and PV production remain the same, but the NP consumption is $66 \mathrm{MWh} /$ year rather than the earlier $73 \mathrm{MWh} /$ year (-10\%). This result represents the (optimised) case where most of the waste heat or renewable heat produced at a building is used within the building itself for heating or hot water production. If energy is used within the building itself, the current formulation of the model considers that no pumping energy is required (equation 17, pipe length equals zero). In the real case, the network pump providing heat to the heat pump and the pump linked to free-cooling can operate simultaneously. Thus regardless of whether the waste heat fed into the LTN by a free-cooling pump is routed back to the same building by the network pump delivering heat to the heat pump; the pumps consume electricity. Thus the monitored NP pump consumption is higher than model results as seen in figure 9 (bottom).

Monitored consumption of the network pumps is significant: it equals $3.2 \%$ of the low temperature heat delivered to HPs; $2.4 \%$ of the total heat demand delivered by HPs for 300 heating and DHW ( $\left.\mathrm{MWh}_{\mathrm{e}} / \mathrm{MWh}_{\mathrm{th}}\right)$; and $4.8 \%$ of the free-cooling supplied. For another LTN in Zurich, Switzerland [17], which does not have bi-directional operation and mainly supplies heating demand, measured values were $1.6 \%$ of the low temperature heat delivered to evaporator of the HPs and $1.2 \%$ of heat delivered by the HPs for heating and DHW. The monitored pumping energy for free-cooling is thus found to be higher than the pumping energy required for heating; this is seen in figure A4, appendix A2. The monitoring data of 
pumping energy for free-cooling buildings in BF5 is more than double the pumping energy for heating the same buildings. Free-cooling demand is higher during summer, when the temperature difference in the LTN is lower, resulting in a higher pumping energy demand.

\section{LTN temperature}

$$
\text { - LTN deltaT }
$$

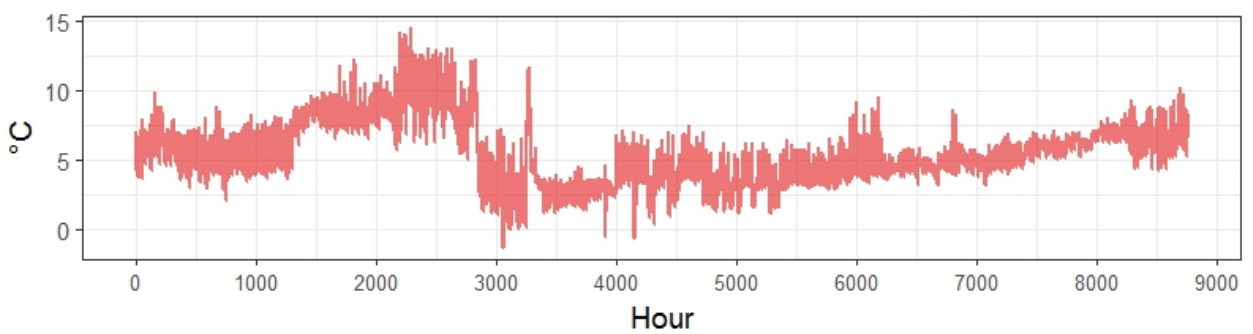

NP electricity consumption

- NP Measured - NP Model

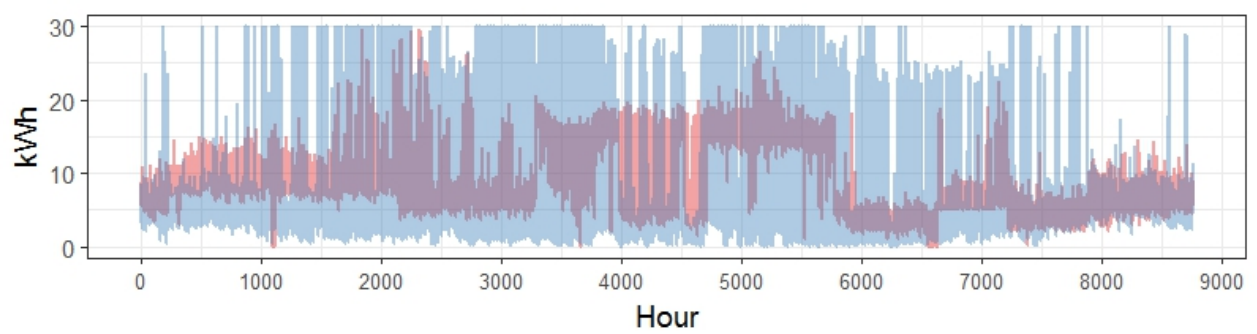

NP electricity consumption selected 9 days profile (hour 1 to 217 )

- NP Measured - NP Model

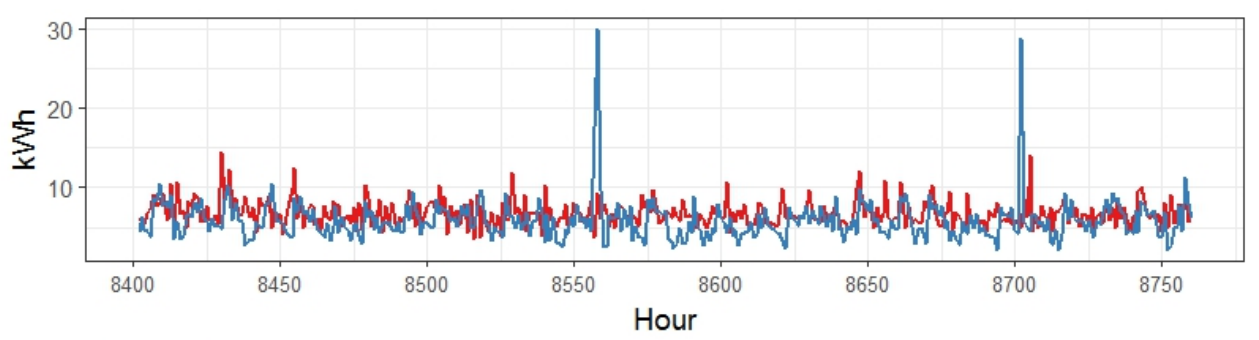

NP median hourly electricity consumption for each month

追 NP Measured 追 NP Model

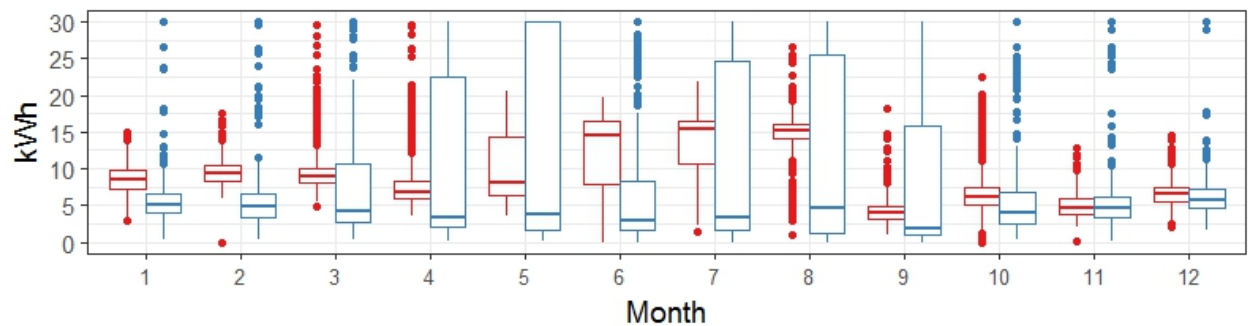

Figure 8. Monitoring data of NP electricity consumption (red) compared with model results (blue). 
LTN temperature

- LTN deltaT

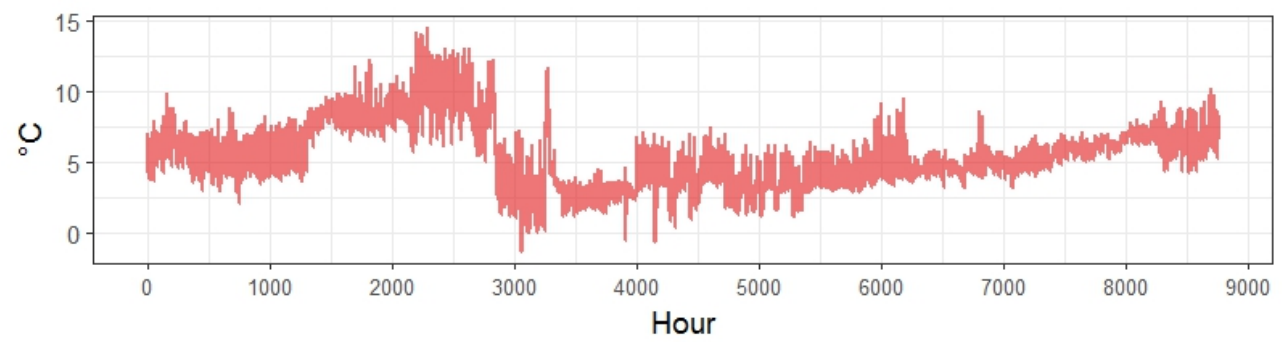

NP electricity consumption

- NP Measured - NP Model (Modified)

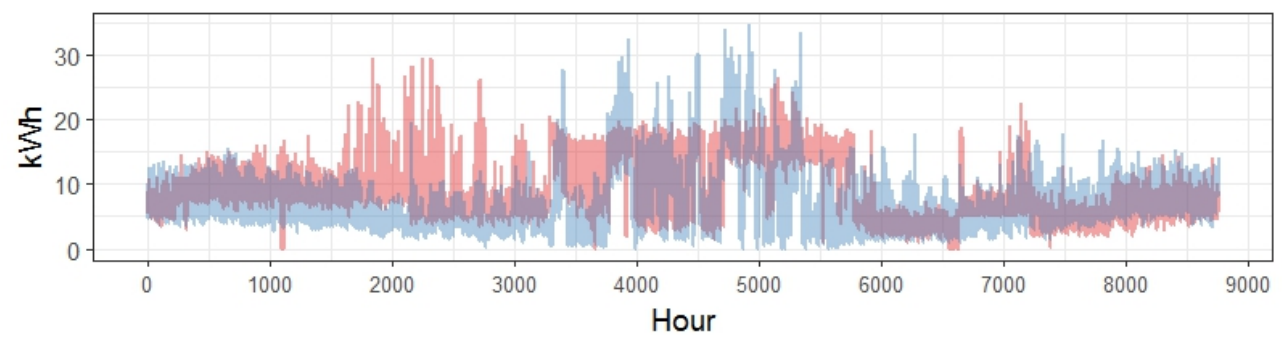

NP electricity consumption selected 9 days profile (hour 1 to 217 )

- NP Measured - NP Model (Modified)

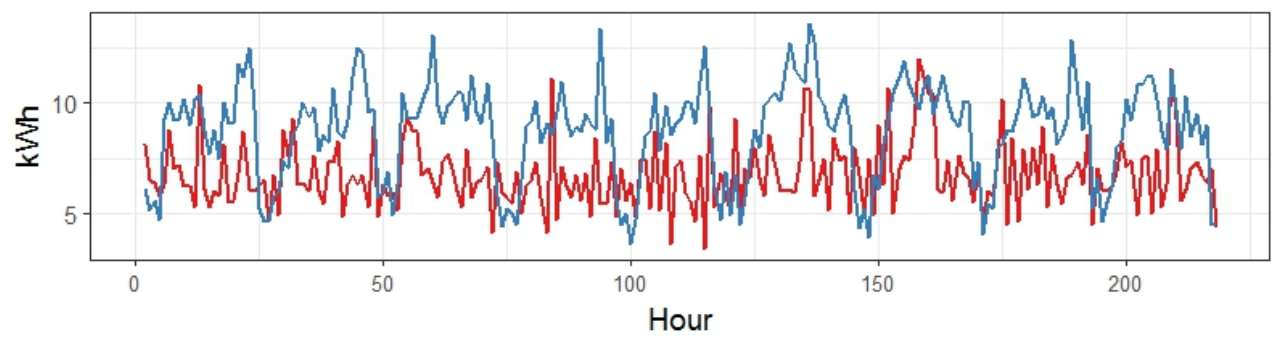

NP median hourly electricity consumption for each month

ウ NP Measured $\risingdotseq$ NP Model (Modified)

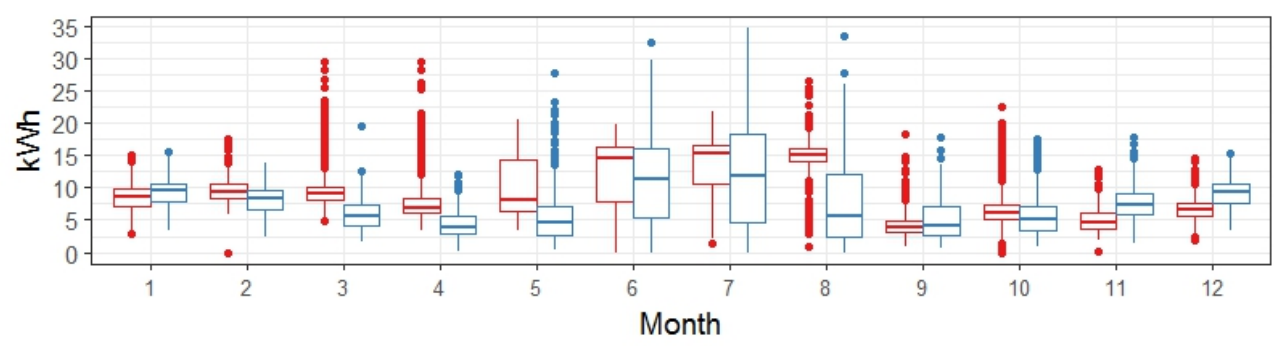

Figure 9. Monitoring data of NP electricity consumption (red) compared with modified model results (blue).

5.4. Comparison of on-site electricity production and consumption for the initial case $(\mathrm{BF} 2+\mathrm{BF} 5)$

An analysis of 15 minute monitoring data of electricity production and electricity consumption of $\mathrm{BF} 2$ and $\mathrm{BF} 5$ is presented in this section. The annual electricity consumption 
for heating and cooling, household devices, and other building services is shown in figure 10. The total solar electricity production of BF2 and BF5 (346 MWh/year) corresponds to $13 \%$ of total electricity demand of these buildings (2653 MWh/year).

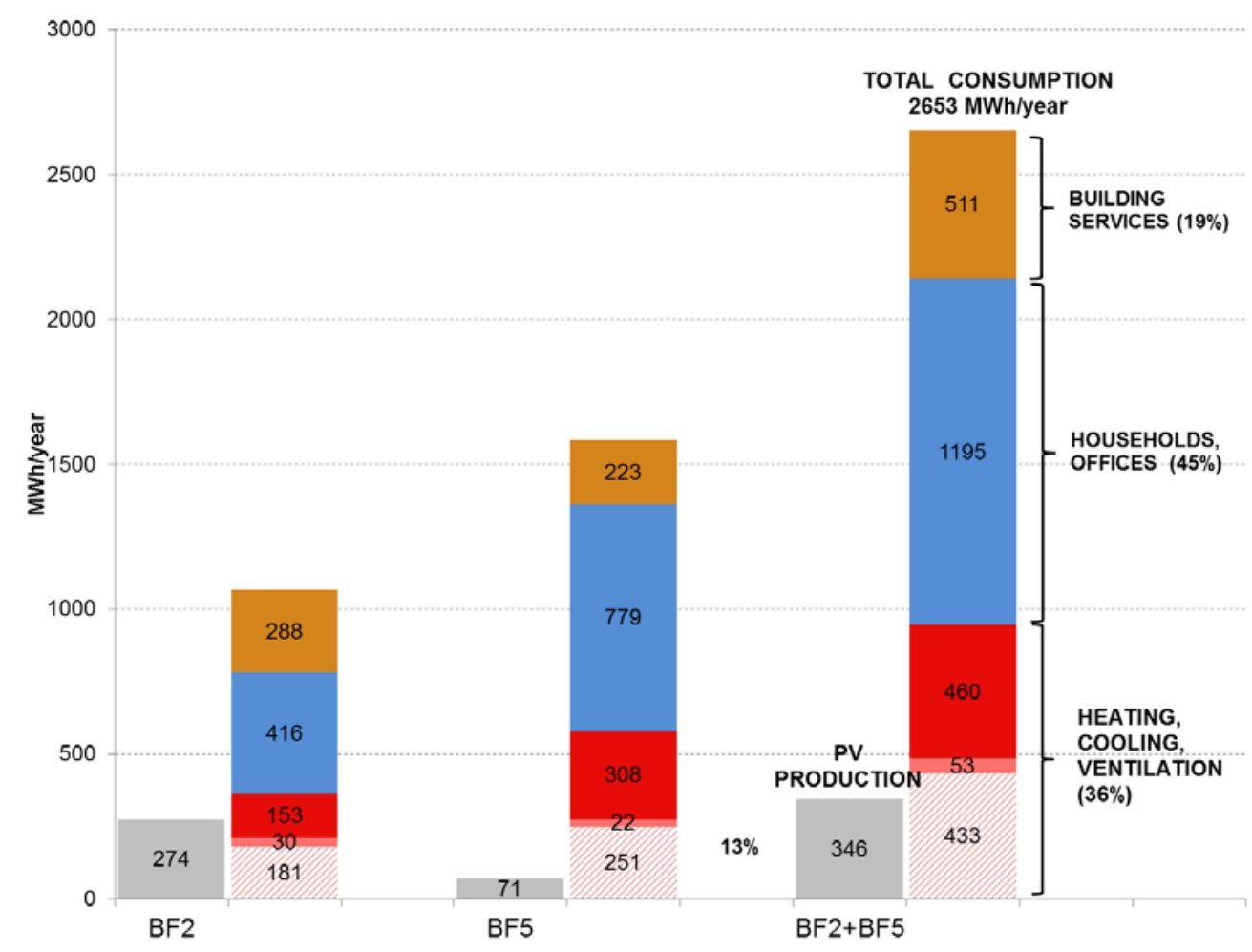

Figure 10. Electricity demand and production of the groups of buildings in BF2 and BF5 in the Suurstoffi district (monitoring data).

Currently, PV electricity produced within the district is only used to cover electricity demand of HPs and NPs, while household and office electricity consumption is purchased from the grid. The electricity production covers $71 \%$ of the electricity demand of HPs and NPs (486 MWh/year).

Performance indicators for net zero electricity buildings [29,30] such as the load cover factor and supply cover factor were calculated for the district using the 15 minute monitoring data. The equations to calculate these indicators are described in the mentioned references. The load cover factor was calculated as the ratio of useable electricity production to the total electricity demand, for 15 minutes intervals, for selected months. The supply cover factor was calculated as the ratio of useable electricity production to the total electricity production for 15 minutes intervals. The average of 15 minute values was calculated to produce the hour based graphs in figure 11. The mean load cover factor over one day for four selected months (representing the four main seasons) is shown in figure 11, top left. The respective supply 
cover factor is shown in figure 10, top right. The load cover factors indicate PV production can cover $60 \%$ to $80 \%$ of the total consumption in certain hours of the day (between 8 am to 6 pm) during summer months, but only $10 \%$ to $15 \%$ in winter months. The supply cover factor is 1 for the selected months, which indicates that $100 \%$ of PV production is used within the district during these months (time step of 15 minute time steps).

The load cover factor and the supply cover factor were also re-calculated considering only the electricity demand of HPs and NPs since these performance indicators are relevant for district stakeholders. The average load cover factor over one day for the same four months is shown in figure 11, bottom left. The corresponding supply cover factor is shown in figure 11, bottom right. The load cover factors indicate $80 \%$ to $100 \%$ of the electricity consumption to produce heat/hot water in (daytime) summer, autumn, and spring is covered by PV production. During winter only $25 \%$ to $30 \%$ of this consumption is covered by PV production.

The average supply cover factor over the day for the same months indicate, during summer almost $60 \%$ to $90 \%$ of PV production cannot be used within the district and is thus sold to the grid. During spring and autumn only about $50 \%$ of the PV production during mid-day can be used within the district. These indicators help planning of future design and operation of the site, especially to identify when to operate HPs and NPs such that a higher percentage of the PV produced can be used within the district. Currently HPs and NPs are not operated to maximise the use of electricity produced within the district. Therefore, in order to evaluate the maximum potential to increase self-consumption, a scenario considering additional heat storage within buildings was considered (section 6). 

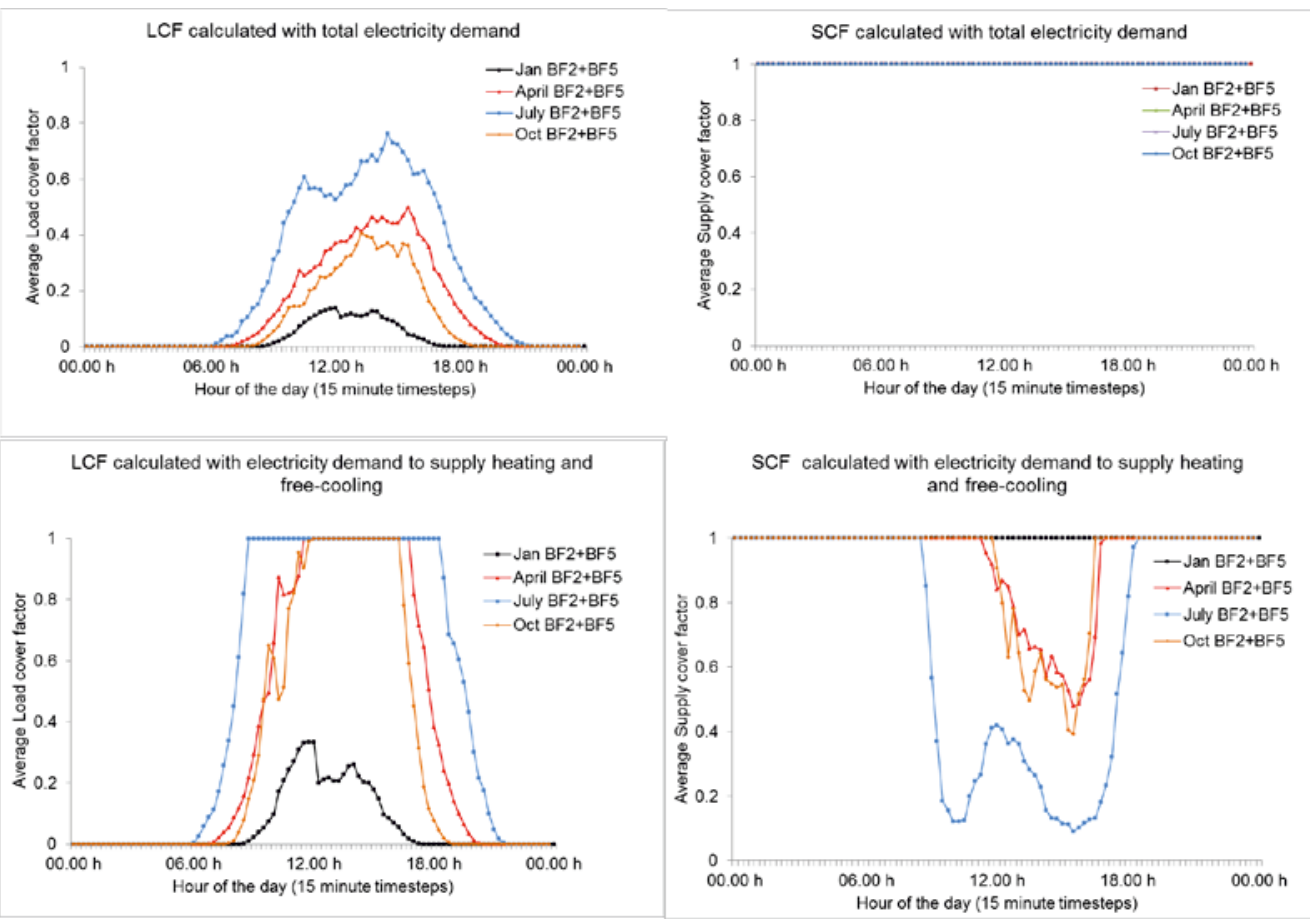

Figure 11. Average load cover factor (LCF) and supply cover factor (SCF) of 15 minutes data intervals calculated for four different months.

\section{Scenarios with electric and thermal storage}

Two scenarios which evaluate the impact of additional (short term) electric and thermal storage were considered with the aim of identifying the potential to increase on-site use of PV produced within the district. The first scenario considered electric storage in the form of batteries installed in the district. An optimisation with an objective function of minimising carbon emissions was carried out with installed battery capacity as a variable.

Two separate models were considered, one in which the network operation was assumed to be unchanged if the battery was installed (equations 35 to 44, appendix A1, monitoring data of electricity consumption was directly used as an input in equation 44)) and the other considering that further improvement of network operation would be possible if a battery was installed in the district. Thus, for the first case considering (fixed) monitoring data of electricity consumption profiles, the maximum (optimal) battery capacity is $819 \mathrm{kWh}$. The maximum battery capacity when considering that the operation of HPs and NPs can be further optimised due to introducing electrical storage is $1383 \mathrm{kWh}$.

The results of optimum battery capacity (with fixed network operation) for different limits on carbon emissions and costs are shown in figure 12. 
The second scenario considered heat storage tanks in all buildings to store hot water for space heating $\left(1000\right.$ litres at $\left.35^{\circ} \mathrm{C}\right)$ and domestic hot water $\left(1000\right.$ litres at $\left.55^{\circ} \mathrm{C}\right)$, (equations 45 to 60, appendix A1). The thermal storage tanks allow the HPs to operate when PV electricity is available and store heat to balance peaks in heat demand and supply.

The results of the scenario optimisation for excess PV production (fed into the grid, or sold to the grid) are found in figure 13. Figure 14 provides the hourly profiles of excess PV production for the different cases considered. Both electric and thermal storage can significantly reduce the amount of PV production fed into the grid, and instead store it for self-consumption at a later time period. In all scenarios, the battery capacity was only charged with electricity produced from the PV panels; i.e. the battery capacity could not be changed with electricity from the grid directly, nor was it allowed to sell electricity to the grid.

When applying these results to the real district, it is important to keep in mind that the optimisation model has limited accuracy. In section 5, the NP operation profiles produced by the model showed an unrealistic on-off operation especially during summer months. Thus the actual reduction in excess electricity production (fed into the grid) is likely to be closer to the case which considers a realistic operation profile of building technologies (the case with a 819 kWh battery and $23 \%$ electricity fed into the grid).

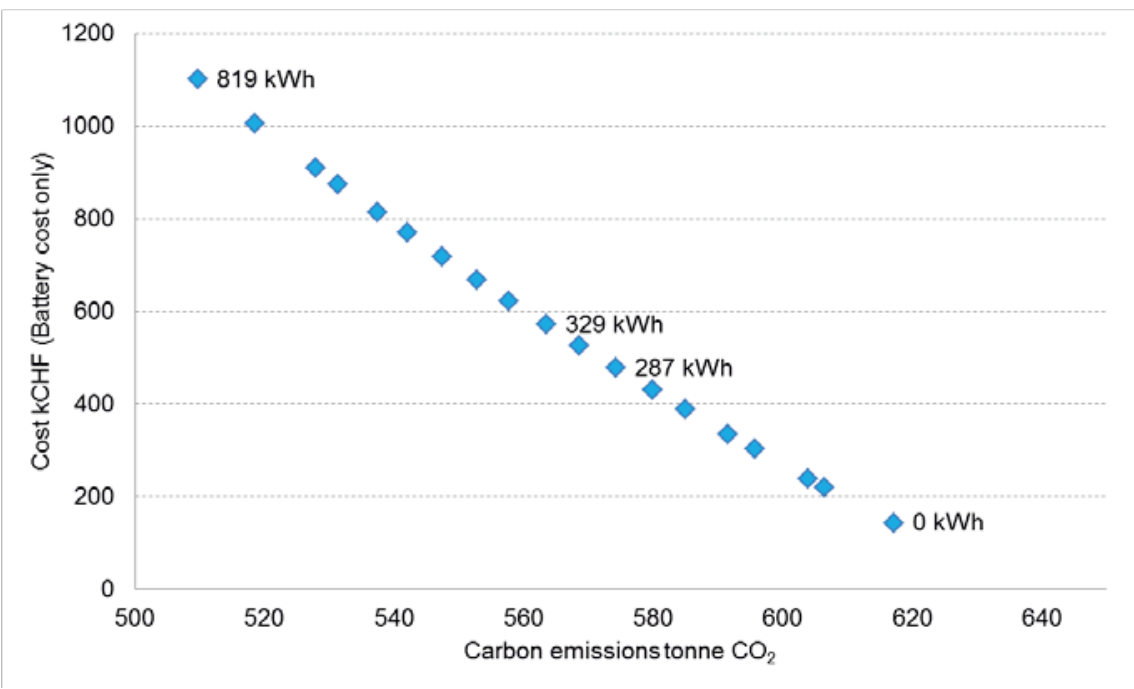

Figure 12. Optimal amount of battery (not considering network optimisation). 


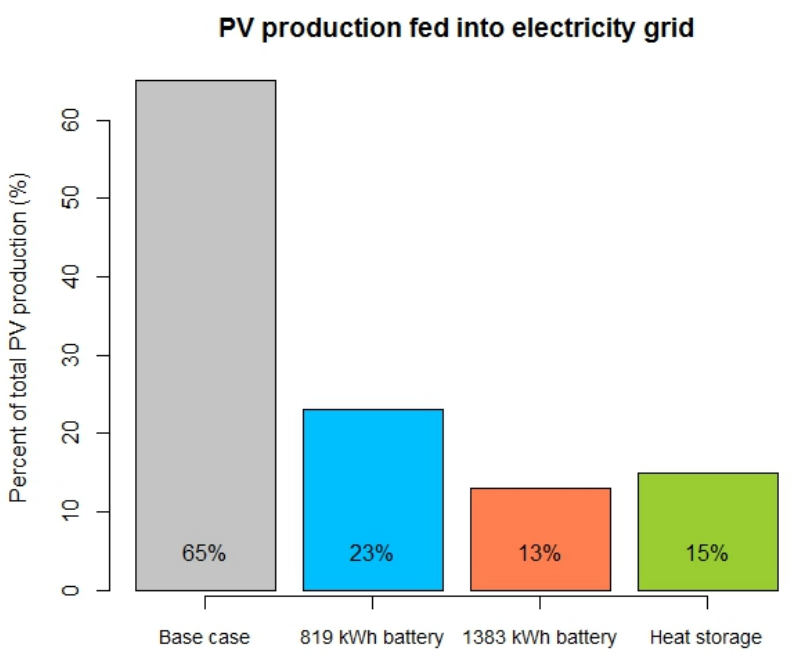

Figure 13. Percentage of excess $P V$ production fed into grid for different scenarios (considering hourly time steps for 1 year).
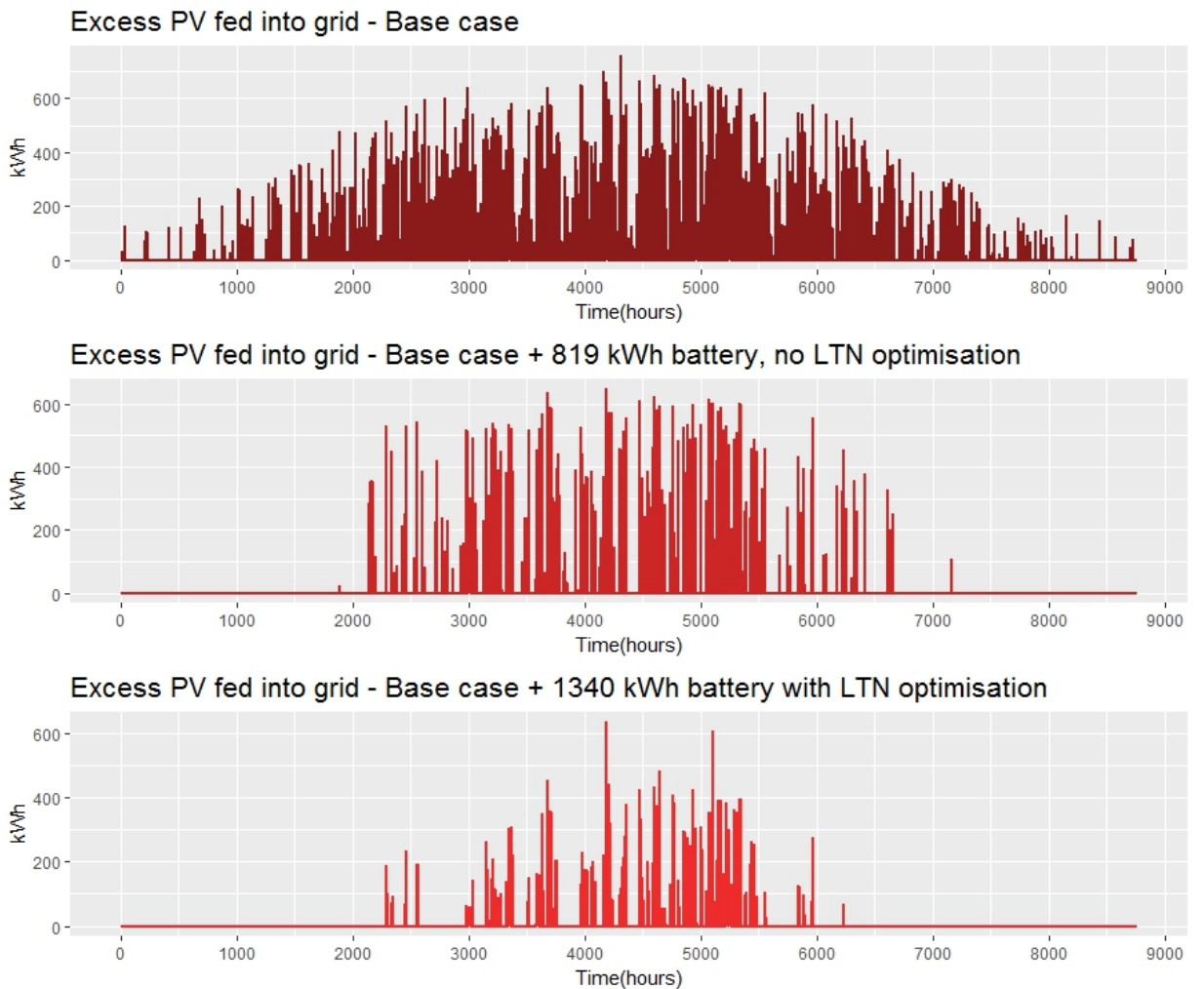

Excess PV fed into grid - Base case + heat storage (2000lt tank in each building)

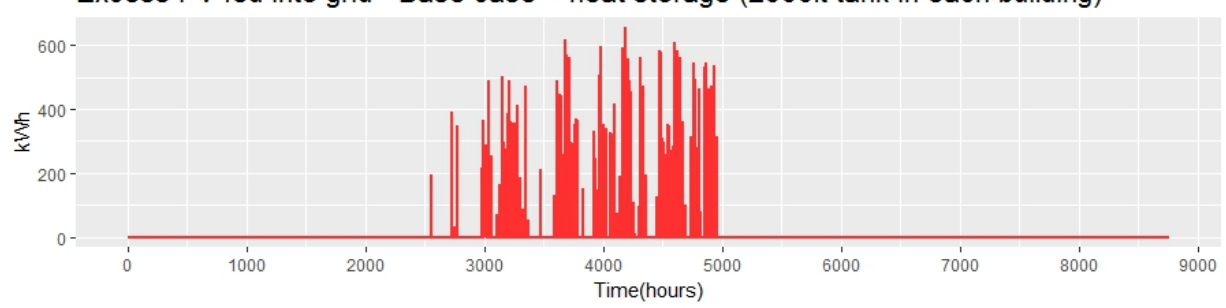

Figure 14. Excess PV fed into grid for different scenarios. 


\section{Discussion}

The DES analysed in this paper has approximately $1000 \mathrm{~kW}_{\mathrm{p}}$ of PV generation capacity (base case). For the initial case with BF2+BF5 only the on-site PV generation can cover $71 \%$ of the annual electricity demand of HPs and NPs (section 5.4). For the base case with $\mathrm{BF} 2+\mathrm{BF} 5+\mathrm{BF} 3$, the combined electricity production of PV and PVT panels should cover $100 \%$ of the annual electricity demand of HPs and NPs. The optimisation of hourly consumption and production of the base case finds only $35 \%$ of this production can be used on-site, while the rest is fed into the electricity grid (figure 13, Base case). This can be increased to $77 \%$ if short term electric or thermal storage is used.

Currently, most districts use annual energy balances (of electricity production and consumption) to obtain sustainability certification. However, revisions to guidelines and certifications for buildings and districts (e.g. nearly zero energy buildings, zero net carbon buildings, etc.) which impose stricter requirements are being considered. Feed in of excess PV production into the grid is generally not a problem for districts. However, with increasing number of buildings and districts with rooftop PV, grid operators might decide to impose additional requirements or curtailment, if sub-stations need to be upgraded to accept decentralised PV production. The payback period of the DES is increased if operation costs which are based on calculations made on annual demand and production are different from reality (due to the time shift in production and consumption). Therefore DES project stakeholders should consider alternative solutions or scenarios for future DES operation.

The results of the scenarios in section 6 highlight the benefits of short term electric or thermal storage by increasing the amount of PV electricity production which can be stored and used on-site. The results also show that even the maximum (optimal) battery capacity cannot store all the electricity produced within the district during certain summer months. While short term storage is beneficial, further increase in the use of on-site PV generation is only possible with seasonal (electric or thermal) storage. While the district has seasonal term thermal storage in the form of the BHS, annual heat supply to the BHS is limited by the maximum charging rate (or mass flow rate) in the BHS as well as the maximum operating temperature of the LTN, which in this case is $22^{\circ} \mathrm{C}$.

The results presented in section 6 indicate that while some of the differences in monitoring data and optimisation model results can be explained due to various assumptions taken in the linear representation, a detailed sensitivity analysis is necessary to better understand the 
relationship between input and output variables of the model. While a brief analysis of the differences observed in annual or monthly results is presented in section 6 , a more detailed explanation of variation at an hourly timescale requires better understanding of the sensitivity of the model to certain input parameters.

It is clear that demand (input) data has a big impact on the results of the model, as well as assumptions related to the performance of the different technologies. Variations in measured consumption profiles with those produced by the model are important, since peak or minimum power consumption of certain system components are important for the selection of storage, and in optimisation of system operation. Other benefits of a sensitivity study would be the possibility to identify errors in the model (unexpected relationships between inputs and outputs) and to further simplify the model by fixing model inputs that have no effect on the output.

\section{Conclusions and future outlook}

One of the aims of this research was to evaluate the energy performance of a district system in terms of renewable energy use and to determine if its LTN operation can be optimised. A secondary aim was to use the multi-energy optimisation framework for a real district and compare our results with data from monitoring. Since few multi-energy optimisation models have been validated so far, this was a first attempt to compare results from a model with monitoring data from a real district. This research work shows it is possible to calibrate and verify an optimisation model with data from monitoring. The model results obtained were reasonably close to monitoring data (keeping in mind the linear approximations used in the model). In addition, model results provided further information about the system, for example the amount of electricity sold to the grid or estimates of electricity consumption of HPs and NPs for buildings (BF3) which were not monitored.

Differences between data from monitoring and model results indicate a potential to improve the current model. It is planned to study this further by developing a simulation model which considers mass flow, pressure drop and dynamic network temperatures as well as energy balance. Future measurements of mass flow and temperature in the LTN will be essential to better model and understand system operation. Also, it is planned to conduct a sensitivity analysis of the existing model. Finally, since few assessments or comparisons of LTNs with traditional DHS have been published, the presented case study will be subsequently compared 
with a hypothetical case study where a centralised DHS supplies the same heating and cooling demands.

Monitoring, multi-energy optimisation models as well as simulation models all play an important role in designing and evaluating DES. Monitoring is necessary to verify building performance criteria, and though it is expensive, monitoring data of certain representative case studies can be used to predict energy performance of similar DES. The multi-energy optimisation approach is useful to select and size storage and conversion technologies for districts, based on criteria defined by stakeholders. Monitored data used as an input to a multienergy optimisation model improves its accuracy and the relevance of its results. Similarly, an iterative exchange of results between simulation and optimisation models would help improve accuracy and provide optimum solutions based on realistic system behaviour.

In conclusion, this case study highlights the importance of developing models which can represent building and district scale and which provide hourly and annual energy balance (production and consumption) of both electricity and heating/cooling. Design and planning of districts is often carried out using calculations which only consider annual or aggregated energy balances. The present analysis shows that calculations made for annual timescales can differ significantly from the results of an optimisation model which provides results at an hourly timescale. In addition, the presented results have an acceptable accuracy when compared to monitoring data. With evolution of new district and network concepts which allow buildings to be prosumers, and further interconnection between electricity and heating systems, evaluation needs to be carried out with higher resolution and complex system interactions need to be considered. Thus a combination of optimisation and simulation methodologies, complemented by energy monitoring is essential to design sustainable buildings and districts.

\section{Acknowledgements}

We acknowledge the contributions by Matthias Sulzer of the Lucerne University of Applied Sciences, Switzerland, in relation to the definition of future scenarios and interpretation of the results.

This research has been financially supported by CTI within the SCCER "Future energy efficient buildings and districts -FEEB\&D” project (CTI.2014.0119). 


\section{References}

[1] EnEff:Stadt, EnEff:Wärme. LowExTra - Low-exergy transmission pipes for storing and distributing heat 2016. http://www.eneff-stadt.info/en/heatingcoolingnetworks/project/details/lowextra-low-exergy-transmission-pipes-for-storing-and-distributingheat/ (accessed October 19, 2016).

[2] Hepbasli A. Low exergy (LowEx) heating and cooling systems for sustainable buildings and societies. Renew Sustain Energy Rev 2012;16:73-104. doi:10.1016/j.rser.2011.07.138.

[3] Stübler A, Bestenlehner D, Drück H. Energy saving potentials of cold district heating networks. 17th EWA Symp., Munich: 2014.

[4] Vetterli N, Thaler E, Sulzer M. Monitoring Suurstoffi. Jahresbericht 2015 (Messperiode Okt. 2014 - Sept. 2015). Hochschule Lucerne ZIG.2016.

[5] Kräuchi P, Schluck T, Sulzer M. Modelling of low temperature heating networks with Ida-Ice. Int. Conf. Clean Technol. Smart Cities Build. CISBAT 2015, Lausanne: 2015, p. $827-32$.

[6] Evins R, Orehounig K, Dorer V, Carmeliet J. New formulations of the "energy hub" model to address operational constraints. Energy 2014;73:387-98.

doi:10.1016/j.energy.2014.06.029.

[7] Orehounig K, Evins R, Dorer V. Integration of decentralized energy systems in neighbourhoods using the energy hub approach. Appl Energy 2015;154:277-89. doi:10.1016/j.apenergy.2015.04.114.

[8] Evins R. A bi-level design and operation optimisation process applied to an energy centre. Build. Simul. Optim. 2014, Building Simulation and Optimization 2014; 2014.

[9] Yang Y, Zhang S, Xiao Y. Optimal design of distributed energy resource systems coupled with energy distribution networks. Energy 2015;85:433-48. doi:10.1016/j.energy.2015.03.101.

[10] Morvaj B, Evins R, Carmeliet J. Optimization framework for distributed energy systems with integrated electrical grid constraints. Appl Energy 2016;171:296-313. doi:10.1016/j.apenergy.2016.03.090. 
[11] Omu A, Choudhary R, Boies A. Distributed energy resource system optimisation using mixed integer linear programming. Energy Policy 2013;61:249-66.

doi:10.1016/j.enpol.2013.05.009.

[12] Weber C, Shah N. Optimisation based design of a district energy system for an ecotown in the United Kingdom. Energy 2011;36:1292-308. doi:10.1016/j.energy.2010.11.014.

[13] Fazlollahi S, Becker G, Maréchal F. Multi-objectives, multi-period optimization of district energy systems: III. Distribution networks. Comput $\{\&\}$ Chem Eng 2014;66:82-97. doi:10.1016/j.compchemeng.2014.02.018.

[14] Morvaj B, Evins R, Carmeliet J. Optimising urban energy systems : simultaneous system sizing, operation and district heating network layout. Energy 2016;116:619-36.

[15] Girardin L, Marechal F, Dubuis M, Calame-Darbellay N, Favrat D. EnerGis: A geographical information based system for the evaluation of integrated energy conversion systems in urban areas. Energy 2010;35:830-40. doi:10.1016/j.energy.2009.08.018.

[16] Verda V, Caccin M, Kona A. Thermoeconomic cost assessment in future district heating networks. Energy 2016:1-7. doi:10.1016/j.energy.2016.07.016.

[17] Ruesch F, Rommel M, Scherer J. Pumping power prediction in low temperature district heating networks. Int. Conf. Clean Technol. Smart Cities Build. CISBAT 2015, Lausanne: 2015 , p. 753-8.

[18] Lund H, Werner S, Wiltshire R, Svendsen S, Thorsen JE, Hvelplund F, et al. 4th Generation District Heating (4GDH). Integrating smart thermal grids into future sustainable energy systems. Energy 2014;68:1-11. doi:10.1016/j.energy.2014.02.089.

[19] Köfinger M, Basciotti D, Schmidt RR, Meissner E, Doczekal C, Giovannini A. Low temperature district heating in Austria: Energetic, ecologic and economic comparison of four case studies. Energy 2015;110:95-104. doi:10.1016/j.energy.2015.12.103.

[20] Ommen T, Markussen WB, Elmegaard B. Lowering district heating temperatures Impact to system performance in current and future Danish energy scenarios. Energy 2016;94:273-91. doi:10.1016/j.energy.2015.10.063.

[21] Brand L, Calvén A, Englund J, Landersjö H, Lauenburg P. Smart district heating networks - A simulation study of prosumers' impact on technical parameters in distribution networks. Appl Energy 2014;129:39-48. doi:10.1016/j.apenergy.2014.04.079. 
[22] Menti U-P, Lüthi D. Monitoring Suurstoffi: Monitoring einer thermischen Arealvernetzung in Kombination mit einem Erdsondenfeld. Hochschule Lucerne ZIG.2012.

[23] Vetterli N, Sulzer M. Dynamic Analysis of the Low-Temperature District Network “ Suurstoffi " Through Monitoring. Cisbat 2015, Lausanne: 2015, p. 517-22. doi:10.5075/epflcisbat2015-517-522.

[24] Vetterli N, Brücker S, Sulzer M. Monitoring Suurstoffi. Jahresbericht 2015 (Messperiode Okt. 2013 - Sept. 2014). Hochschule Lucerne ZIG. 2015.

[25] Menezes AC, Cripps A, Bouchlaghem D, Buswell R. Predicted vs. actual energy performance of non-domestic buildings: Using post-occupancy evaluation data to reduce the performance gap. Appl Energy 2012;97:355-64. doi:10.1016/j.apenergy.2011.11.075.

[26] De Wilde P. The gap between predicted and measured energy performance of buildings: A framework for investigation. Autom Constr 2014;41:40-9. doi:10.1016/j.autcon.2014.02.009.

[27] Maroufmashat A, Fowler M, Sattari Khavas S, Elkamel A, Roshandel R, Hajimiragha A. Mixed integer linear programing based approach for optimal planning and operation of a smart urban energy network to support the hydrogen economy. Int J Hydrogen Energy 2016;41:7700-16. doi:10.1016/j.ijhydene.2015.08.038.

[28] Geidl M, Andersson G. Optimal coupling of energy infrastructures. 2007 IEEE Lausanne Power Tech, IEEE; 2007, p. 1398-403. doi:10.1109/PCT.2007.4538520.

[29] Salom J, Marszal AJ, Widen J, Candanedo J, Lindberg KB. Analysis of load match and grid interaction indicators in net zero energy buildings with simulated and monitored data. Appl Energy 2014;136:119-31. doi:10.1016/j.apenergy.2014.09.018.

[30] Salom J, Marszal AJ, Candanedo J, Widen J, Lindberg KB, Sartori I. Analysis of load match and grid interaction indicators in net zero energy buildings with high resolution data. 2014. 



\section{Appendix A1}

The equations below describe the various conversion technologies, heat and electricity storage, and network energy balances for the complete DES model. These equations represent the initial case model, as well as the base case mode and modified equations used in scenarios are indicated below.

Indices

$\mathrm{i}, \mathrm{j}$ : indices with represent nodes in the network

t: hourly time steps

The electricity produced by panels installed on buildings in BF2 is a function of installed PV area, efficiency and solar radiation.

PV

$P_{i, t}^{P V}=A_{i}^{P V} * n_{P V} * P_{i, t}^{\text {solar }}$

$\forall \mathrm{i} \in$ building nodes with $\mathrm{PV}, \mathrm{t}$

$P_{i, t}^{P V}=P_{i, t}^{P V S E L F}+P_{i, t}^{P V S E L L}$

$\forall \mathrm{i} \in$ building nodes with $\mathrm{PV}, \mathrm{t}$

where,

$P_{i, t}^{P V}$ : Electricity produced by $\mathrm{PV}[\mathrm{kWh}]$

$A_{i}^{P V}:$ Area of PV installed on building $\left[\mathrm{m}^{2}\right]$

$n_{P V}:$ Efficiency of PV [\%]

$P_{i, t}^{\text {solar }}$ : Solar irradiation $\left[\mathrm{kWh} / \mathrm{m}^{2}\right]$

$P_{i, t}^{P V S E L F}$ : Electricity produced by PV used within the district or building [kWh]

$P_{i, t}^{P V S E L L}$ : Excess electricity produced by PV sold to the grid or fed into the grid [kWh]

The electricity produced by hybrid panels installed on buildings in BF3 is a function of installed PVT area, electrical efficiency and solar radiation. The heat produced by hybrid panels installed on buildings in BF3 is a function of installed PVT area, thermal efficiency and solar radiation.

PVT

$P_{i, t}^{P V T \text { electric }}=A_{i}^{P V T} * n_{P V T}$ electric $* P_{i, t}^{\text {solar }}$

$\forall \mathrm{i} \in$ building nodes with PVT, $\mathrm{t}$

$P_{i, t}^{P V T \text { electric }}=P_{i, t}^{P V T \text { electric SELF }}+P_{i, t}^{P V T \text { electric SELL }}$ 
$\forall \mathrm{i} \in$ building nodes with PVT, $\mathrm{t}$

$P_{i, t}^{P V T \text { heat }}=A_{i}^{P V T} * n_{t}^{\text {PVT heat }} * P_{i, t}^{\text {solar }}$

$\forall \mathrm{i} \in$ building nodes with PVT, $\mathrm{t}$

where,

$P_{i, t}^{P V T}$ electric $:$ Electricity produced by PVT $[\mathrm{kWh}]$

$A_{i}^{P V T}:$ Area of PVT installed on building $\left[\mathrm{m}^{2}\right]$

$n_{P V T \text { electric }}$ : Electrical efficiency of PVT [\%]

$n_{t}^{P V T}$ heat: Thermal efficiency of PVT varying with time of the year [\%]

$P_{i, t}^{P V T}$ electric SELF : Electricity produced by PVT used within the district or building [kWh]

$P_{i, t}^{P V T}$ electric SELL $:$ Excess electricity produced by PVT sold to the grid or fed into the grid $[\mathrm{kWh}]$

$P_{i, t}^{P V T \text { battery }}$ : Electricity produced by PVT stored in the battery [kWh]

$P_{i, t}^{P V T}$ heat $:$ Heat produced by PVT $\left[\mathrm{kWh}_{\mathrm{th}}\right]$

Heat pumps

The electricity consumed by the two stage heat pump is dependent on the COP, delivered loads, and heat input. The COP used is an average COP for the two stages.

$P_{i, t}^{H P \text { elec }} \leq P_{i}^{H P \text { capacity }}$

$\forall \mathrm{i} \in$ building nodes, $\mathrm{t}$

$\operatorname{COP}_{i}^{H P}=\frac{{\text { Heat } \text { load }_{i, t}+\text { DHW } \text { load }_{i, t}}_{P_{i, t}^{H P e l e c}}}{\text { ele }}$

$\forall \mathrm{i} \in$ building nodes, $\mathrm{t}$

$P_{i, t}^{H P \text { elec }}+P_{i, t}^{H P \text { heat }}=$ Heat $\operatorname{load}_{i, t}+$ DHW $\operatorname{load}_{i, t}$

$\forall \mathrm{i} \in$ building nodes, $\mathrm{t}$

where,

$P_{i}^{H P \text { capacity }}:$ Installed capacity of heat pump [kW]

$P_{i, t}^{H P \text { elec }}$ : Work done by heat pump/Electricity consumption of heat pump [kWh]

$P_{i, t}^{H P \text { heat }}$ : Thermal input to heat pump $\left[\mathrm{kWh}_{\mathrm{th}}\right]$

$C O P_{i}^{H P}$ : Coefficient of performance of heat pump when producing heat 
Heat $\operatorname{load}_{i, t}$ : Space heating loads, per building [ $\left.\mathrm{kWh}_{\mathrm{th}}\right]$

DHW $\operatorname{load}_{i, t}$ : Domestic hot water loads, per building [ $\left[\mathrm{kWh}_{\mathrm{th}}\right]$

Borehole field

The borehole field is represented as three thermal storages located at three entry points of the real field.

$E_{i, t}^{S O C B H S} \leq E_{i}^{B H S c a p}$

$\forall \mathrm{i} \in$ BHS nodes, $\mathrm{t}$

$E_{i, t+1}^{S O C B H S}=E_{i, t}^{S O C B H S} * n_{B H S S L}+Q_{i, t}^{\text {charge BHS }} * n_{B H S \text { charge }}-\left(\frac{1}{n_{B H S \text { discharge }}}\right) *$

$Q_{i, t}^{\text {discharge } B H S}$

$\forall \mathrm{i} \in$ BHS nodes, $\mathrm{t}$

$Q_{i, t}^{\text {Charge BHS }} \leq C_{\text {Max_charge }}$

$\forall \mathrm{i} \in$ BHS nodes, $\mathrm{t}$

$Q_{i, t}^{\text {Discharge BHS }} \leq c_{\text {Max_discharge }}$

$\forall \mathrm{i} \in$ BHS nodes, $\mathrm{t}$

$Q_{i, t}^{\text {Disharge BHS }}=\Sigma_{j}\left(L T N_{i, j, t}^{\text {out }}\right)$

$\forall \mathrm{i} \in$ BHS nodes, $\mathrm{t}$

$Q_{i, t}^{\text {Charge BHS }}=\Sigma_{j}\left(L T N_{j, i, t}^{i n} * f_{i, j}^{\text {heatloss }}\right)$

$\forall \mathrm{i} \in$ BHS nodes, $\mathrm{t}$

where,

$E_{i, t}^{S O C B H S}:$ State of charge of borehole field entrance node $[\mathrm{kW}]$

$E_{i}^{B H S c a p}:$ Total capacity of borehole field to store heat, divided by 3 (three borehole entry nodes) $[\mathrm{kW}]$

$Q_{i, t}^{\text {Charge BHS }}$ : Charging energy of borehole field $\left[\mathrm{kWh}_{\mathrm{th}}\right]$

$Q_{i, t}^{\text {Discharge BHS }}$ : Discharging energy of borehole field $\left[\mathrm{kWh}_{\mathrm{th}}\right]$

$n_{B H S S L}$ : Standing losses in borehole field [\%]

$n_{B H S}$ charge: Losses due to charge of borehole field [\%]

$n_{B H S}$ discharge $:$ Losses due to discharge of borehole field [\%] 
$B H S_{\text {Max_charge_constant }}$ : Maximum capacity at which borehole field can be charged [kW]

BHS $S_{\text {Max_charge_constant }}$ : Maximum capacity at which borehole field can be discharged [kW]

$\operatorname{LTN}_{j, i, t}^{i n}:$ Heat energy from low temperature network to nodes $\left[\mathrm{kWh}_{\mathrm{th}}\right]$

$L T N_{i, j, t}^{\text {out }}$ : Heat energy from nodes to low temperature network $\left[\mathrm{kWh}_{\mathrm{th}}\right]$

$f_{i, j}^{\text {heatloss }}$ : Reduction factor due to heat loss along pipe connecting nodes $\mathrm{i}$ and $\mathrm{j}[\%]$

Network pumps

Power required for transmission of pumped fluid energy can be defined as

$E_{\text {pump }}=\rho * g * \dot{V} * H$

where,

$E_{\text {pump }}$ : Power consumed by pump [W]

$\rho$ : Density of pumped medium (water) $\left[\mathrm{kg} / \mathrm{m}^{3}\right]$

$\dot{V}$ : Volumetric flow rate $\left[\mathrm{m}^{3} / \mathrm{s}\right]$

$g:$ Acceleration due to gravity $\left[\mathrm{m} / \mathrm{s}^{2}\right]$

$\mathrm{H}:$ Total head $[\mathrm{m}]$

From the Darcy-Weisbach equation, the total head $\mathrm{H}$ is calculated as

$H=f_{D} * \frac{8 L}{\pi^{2} g} * \frac{\dot{V}^{2}}{D^{5}}$

where,

$f_{D}:$ Friction factor

$L$ : Length of pipe $[\mathrm{m}]$

$D$ : Inner diameter of pipe $[\mathrm{m}]$

After substitution and simplification of the Darcy-Weisbach equation, the pumping energy is found to be inversely related to the cube of $\Delta T$ and proportionally related to the cube of energy transfer through a pipe. Since the equation has to be expressed in linear form, it has been simplified such that pumping energy is proportionally related to the energy transfer through a pipe and the length of the pipe. $\Delta T$ and the mass flow rate are assumed to be constant.

$P_{i, t}^{\text {pump }} * n_{\text {pump }}=\Sigma_{j}\left(L T N_{i, j, t}^{\text {out }} *\right.$ pipe length $\left.h_{i, j}\right) * c_{\text {pump }}$

$\forall \mathrm{i}, \mathrm{t}$ 
$\Sigma_{i}\left[P_{i}^{\text {pump }}\right] \leq P^{\text {pump cap }}$

$\forall \mathrm{i}, \mathrm{t}$

where,

$P_{i, t}^{\text {pump }}:$ Electricity consumption of network pumps [kWh]

$n_{\text {pump }}:$ Total efficiency of pumps [\%]

pipe $_{i, j}$ : Length of pipes connecting buildings [m]. In this paper it is defined based on a plan of the actual network.

$c_{\text {pump }}$ : Constant calculated from diameter of pipe, $\Delta \mathrm{T}$, etc., based on above equations. In this paper it is determined by calibration with monitoring data of winter months.

$P^{\text {pump cap }}$ : Total installed capacity of pumps [kW]

Modified network pumps definition

$P_{i, t}^{\text {pump cool }} * n_{\text {pump }}=\Sigma_{j}\left(L T N_{i, j, t}^{\text {out }} *\right.$ pipe $\left._{i, j}\right) * c_{\text {pump cool }}$

$\forall \mathrm{i} \in$ building nodes, $\mathrm{t}$

$P_{i, t}^{\text {pump heat }} * n_{\text {pump }}=\Sigma_{j}\left(L T N_{i, j, t}^{\text {out }} *\right.$ pipe $\left._{i, j}\right) * c_{\text {pump heat }}$

$\forall \mathrm{i} \in$ building nodes, $\mathrm{t}$

$P_{i}^{\text {pump }}=P_{i, t}^{\text {pump heat }}+P_{i, t}^{\text {pump cool }}$

$\forall \mathrm{i} \in$ building nodes, $\mathrm{t}$

where,

$P_{i, t}^{\text {pump cool }}$ : Electricity demand of network pumps to supply free-cooling [kWh]

$P_{i, t}^{\text {pump heat }}$ : Electricity demand of network pumps to supply low temperature heat $[\mathrm{kWh}]$

$c_{\text {pump cool }}$ : Constant determined by calibration with monitoring data of pumping energy to supply free-cooling

$c_{\text {pump heat }}$ : Constant determined by calibration with monitoring data of pumping energy to supply heat input to heat pumps

LTN pipes/ connections between nodes

Heat is transferred from one network node to another only if there is a connection (pipeline) between the two nodes.

$L T N_{i, j, t}^{\text {out }} \leq B i g M * \delta_{i, j}^{\text {pipe }}$ 
$\forall \mathrm{i}, \mathrm{j}$; where $\mathrm{j} \neq \mathrm{i}$

$f_{i, j}^{\text {heatloss }}=1-\left(2 \% *\right.$ pipe $\left._{i, j}\right) / 1000$

$\forall \mathrm{i}, \mathrm{j}$

$\delta_{i, j}^{\text {pipe }}$ : Binary parameter which defines if two nodes in the network are connected with a pipeline. $\mathrm{i}$, and $\mathrm{j}$ are indices which define nodes.

Big M: Sufficiently large number which is selected based on problem data.

Routing nodes

Routing nodes are used to describe locations at which there is branching of pipelines. Energy is neither converted nor stored at these nodes, and energy balance is made across these nodes.

$\Sigma_{j}\left(L T N_{i, j, t}^{\text {out }}\right)=\Sigma_{j}\left(\operatorname{LTN}_{j, i, t}^{\text {in }} * f_{i, j}^{\text {heatloss }}\right)$

$\forall \mathrm{i} \in$ routing nodes, $\mathrm{j}, \mathrm{t}$

Electricity balance

The electricity produced by the PV and PVT plus the electricity imported from the grid is used to supply the consumption of heat pumps and network pumps.

$\Sigma_{i}\left(P_{i, t}^{\text {grid import }}+P_{i, t}^{P V S E L F}+P_{i, t}^{P V T \text { electric } S E L F}\right)=\Sigma_{i}\left(P_{i, t}^{H P \text { elec }}+P_{i, t}^{\text {pump }}\right)$

$\forall \mathrm{t}$

where,

$P_{i, t}^{\text {grid import }}$ : Amount of electricity purchased from the grid [kWh]

Network energy (heat) balance

An energy balance of heat inputs and heat outputs is made at each building. Thus heat input to a building node is only necessary if the building does not produce waste heat or heat from PVT. Similarly, waste heat from free-cooling is only sent to another network node if it is not needed within the building during the same time-step.

$\Sigma_{j}\left(L T N_{i, j, t}^{\text {out }}\right)+P_{i, t}^{H P \text { heat }}=\Sigma_{j}\left(L T N_{j, i, t}^{i n} * f_{i, j}^{\text {heatloss }}\right)+P_{i, t}^{\text {Free-coolng }}+P_{i, t}^{\text {PVT heat }}$

$\forall \mathrm{i} \in$ building nodes, $\mathrm{t}$

$\Sigma_{j}\left(L T N_{i, j, t}^{\text {out }}\right)=P_{i, t}^{\text {Free-coolng }}+P_{i, t}^{\text {PVT heat }}$

$\forall \mathrm{i} \in$ building nodes, $\mathrm{t}$

$\Sigma_{j}\left(L T N_{j, i, t}^{i n}\right)=P_{i, t}^{H P}$ heat

$\forall \mathrm{i} \in$ building nodes, $\mathrm{t}$ 
where,

$P_{i, t}^{\text {Free-coolng }}$ : Waste heat produced due to free-cooling of buildings, per building, per time step $[\mathrm{kWh}]$

Costs

Total costs of the district are the sum of investment costs and operational costs. The investment costs are considered to be zero, since the site is already built, and no design optimisation (installation of new conversion technology) is required.

$C_{\text {Inv }}=0$

$C_{O p}=\sum_{i} \sum_{t}\left[\left(C_{i, t}^{\text {grid import }} * P_{i, t}^{\text {grid import }}\right)-C^{\text {grid export }} *\left(P_{i, t}^{P V S E L L}+P_{i, t}^{P V T \text { electric SELL }}\right)\right] *$ NPV

$C_{\text {total }}=C_{\text {Inv }}+C_{o p}$

where,

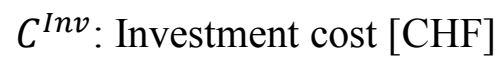

$C^{\text {Total }}:$ Total cost of project $[\mathrm{CHF}]$

$C^{O p}:$ Operational costs of project $[\mathrm{CHF}]$

$C_{i, t}^{\text {grid import }}$ : Cost of electricity purchased from the grid [CHF/kWh]

$C^{\text {grid export }}$ : Cost of electricity sold to the grid [CHF/kWh]

$N P V$ : Net present value

Carbon emissions

The total carbon emissions produced by the district (for DES system operation) is equal to the carbon emissions of total imported electricity of the grid times the emission factor of the grid.

Carbon $_{\text {total }}=\sum_{i} \sum_{t}\left(C F_{\text {grid }} * P_{i, t}^{\text {grid import }}\right)$

where,

Carbon $_{\text {total }}$ : Total carbon emissions of the project

$C F_{\text {grid }}$ : Carbon factor for grid electricity $\left[\mathrm{kg} \mathrm{CO}_{2} / \mathrm{kWh}\right]$

Scenario with battery

In the scenario with a battery, new variables which quantify the amount of electricity from renewable production which is used to charge the battery are defined. Thus equation 2 and equation 4 are appropriately modified.

$P_{i, t}^{P V}=P_{i, t}^{P V S E L F}+P_{i, t}^{P V S E L L}+P_{i, t}^{P V \text { battery }}$ 
$\forall \mathrm{i} \in$ building nodes with $\mathrm{PV}, \mathrm{t}$

$P_{i, t}^{P V \text { battery }}$ : Electricity produced by PV stored in the battery [kWh]

$P_{i, t}^{P V T}=P_{i, t}^{P V T S E L F}+P_{i, t}^{P V T S E L L}+P_{i, t}^{P V T \text { battery }}$

$\forall \mathrm{i} \in$ building nodes with PVT, $\mathrm{t}$

Electric storage (battery)

The battery is described as an electrical storage installed at district level. Since its geographical location does not matter, it is defined without a node index.

$P_{t}^{S O C} \leq P^{\text {Battery cap }}$

$\forall \mathrm{t}$

$P_{t}^{S O C} \geq P^{\text {Batterycap }} * P^{\min S O C}$

$P_{t+1}^{S O C}=$

$P_{t}^{S O C} * n_{\text {battery } S L}+P_{t}^{\text {Battery charge }} * n_{\text {battery charge }}-$

$\left(\frac{1}{n_{\text {battery discharge }}}\right) * P_{t}^{\text {Battery discharge }}$

$\forall \mathrm{t}$

$P_{t}^{\text {Battery charge }} \leq P^{\text {Battery capacity }} * C_{\text {max }_{\text {c }} \text { charge_rate }}$

$\forall \mathrm{t}$

$P_{t}^{\text {Battery discharge }} \leq P^{\text {Battery capacity }} * C_{\text {max }_{\_} \text {discharge_rate }}$

$\forall \mathrm{t}$

$P_{t}^{\text {Battery SOC }}=P_{t}^{\text {Battery SOC }}$

$\forall \mathrm{t} \in$ first and last time step

$P_{t}^{\text {Battery charge }}=\Sigma_{i}\left(P_{i, t}^{\text {PVT battery }}+P_{i, t}^{P V \text { battery }}\right)$

$\forall \mathrm{t}$

$P_{t}^{\text {Battery discharge }} \leq \Sigma_{i}\left(P_{i, t}^{H P \text { elec }}+P_{i, t}^{\text {pump }}\right)$

$\forall \mathrm{t}$

where,

$P_{t}^{\text {Battery SOC }}$ : State of charge of battery [kW]

$P^{\text {Battery capacity }}$ : Capacity of installed battery [ $\left.\mathrm{kWh}\right]$

$n_{\text {battery } S_{L}}$ : Standing losses for battery [\% of capacity] 
$n_{\text {battery charge: }}$ Charging efficiency of battery [\% of capacity]

$n_{\text {battery discharge }}$ : Discharging efficiency of battery [\% of capacity]

$P_{t}^{\text {Battery charge }}$ : Battery charging energy $[\mathrm{kWh}]$

$P_{t}^{\text {Battery discharge }}$ : Battery discharging energy $[\mathrm{kWh}]$

$C_{\text {max_charge_rate: }}$ Maximum charging rate of the battery [\% of capacity]

$c_{\text {max_discharge_rate }}$ : Maximum discharging rate of the battery [ $\%$ of capacity]

$P^{\min S O C}$ : Minimum state of charge of the battery [\% of capacity]

In the battery scenario, the investment cost of the battery is considered using a linear cost for battery capacity. This cost is assumed to take into account the installation cost as well as costs of additional required equipment. Thus equation 25 is modified to equation 39 .

$C_{\text {Inv }}=B_{L C} * P^{\text {Battery cap }}$

$B_{L C}$ : Linear cost of battery installation $[\mathrm{CHF} / \mathrm{kWh}]$

In the battery scenario, excess electricity produced by PV and PVT panels is used to charge the battery. The battery then discharges at a later time to supply electricity consumption of the technical equipment. Thus equation 22 is modified to equation 40. Simultaneous charge and discharge of the battery is constrained by higher losses when this occurs.

$\Sigma_{i}\left(P_{i, t}^{\text {grid import }}+P_{i, t}^{P V S E L F}+P_{i, t}^{\text {PVT electric SELF }}\right)+P_{i, t}^{\text {Battery discharge }}-P_{i, t}^{\text {Battery charge }}=$

$$
\Sigma_{i}\left(P_{i, t}^{H P \text { elec }}+P_{i, t}^{\text {pump }}\right)
$$

Heat Storage (two storage tanks in each building at $35^{\circ} \mathrm{C}$ and $55^{\circ} \mathrm{C}$ )

In the scenario with heat storage, two storage tanks (1000 lt each) store water after the heat pump, for space heat $\left(\right.$ at $35^{\circ} \mathrm{C}$ ) and domestic hot water (at $55^{\circ} \mathrm{C}$ ).

Thus the two storage tanks are defined as heat stores located at building nodes.

Heat store at $35^{\circ} \mathrm{C}$

$E_{i, t}^{S H}$ store $S O C \leq E_{i}^{S H}$ store capacity

$\forall \mathrm{i} \in$ building nodes, $\mathrm{t}$

$E_{i, t}^{S H \text { store } S O C} \geq E_{i}^{\text {SH store capacity }} * E^{\text {SH store } \min S O C}$

$\forall \mathrm{i} \in$ building nodes, $\mathrm{t}$

$E_{i, t+1}^{S H \text { store } S O C}=E_{i, t}^{S H}$ store $S O C * n_{S H \text { store standing loss }}+Q_{i, t}^{S H}$ store $* n_{S H \text { store charging eff }}-$
$\left(\frac{1}{n_{S H} \text { store discharging eff }}\right) * Q_{i, t}^{S H}$ store discharge

$\forall \mathrm{i} \in$ building nodes, $\mathrm{t}$ 
$Q_{i, t}^{S H \text { store charge }} \leq E_{i}^{\text {SH store capacity }} * r_{\text {max }_{\text {_charge }}}$

$\forall \mathrm{i} \in$ building nodes, $\mathrm{t}$

$Q_{i, t}^{\text {SH store discharge }} \leq E_{i}^{\text {SH store capacity }} * r_{\text {max_discharge }}$

$\forall \mathrm{i} \in$ building nodes, $\mathrm{t}$

$E_{i, t}^{S H}$ store $S O C=E_{i, t}^{S H}$ store $S O C$

$\forall \mathrm{i} \in$ building nodes, $\mathrm{t} \in$ first and last time step

$Q_{i, t}^{\text {SH store discharge }} \geq$ Heat load $_{i, t}$

$\forall \mathrm{i} \in$ building nodes, $\mathrm{t}$

where,

$E_{i, t}^{S H}$ store SOC $:$ State of charge of heat storage at $35^{\circ} \mathrm{C}[\mathrm{kW}]$

$E_{i}^{\text {SH store capacity }}:$ Capacity of installed heat storage at $35^{\circ} \mathrm{C}[\mathrm{kW}]$

$n_{S H}$ store standing loss $:$ Standing losses for heat storage at $35^{\circ} \mathrm{C}$ [\% of capacity]

$n_{S H}$ store charging eff : Charging efficiency of heat storage at $35^{\circ} \mathrm{C}$ [\% of capacity]

$n_{S H}$ store discharging eff : Discharging efficiency of heat storage at $35^{\circ} \mathrm{C}$ [ $\%$ of capacity]

$Q_{i, t}^{S H}$ store charge $:$ Heat storage at $35^{\circ} \mathrm{C}$ charging energy $\left[\mathrm{kWh}_{\mathrm{th}}\right]$

$Q_{i, t}^{S H}$ store discharge $:$ Heat storage at $35^{\circ} \mathrm{C}$ discharging energy $\left[\mathrm{kWh}_{\mathrm{th}}\right]$

$r_{\text {max_charge }}$ : Maximum charging rate of the heat storage at $35^{\circ} \mathrm{C}$ [\% of capacity]

$r_{\text {max } \_ \text {discharge }}:$ Maximum discharging rate of the heat storage at $35^{\circ} \mathrm{C}$ [ $\%$ of capacity]

$E^{S H}$ store min $S O C$ : Minimum state of charge for heat storage at at $35^{\circ} \mathrm{C}[\%$ of capacity]

Heat store at $55^{\circ} \mathrm{C}$

$E_{i, t}^{D H}$ store $S O C \leq E_{i}^{D H}$ store capacity

$\forall \mathrm{i} \in$ building nodes, $\mathrm{t}$

$E_{i, t}^{D H}$ store $S O C=E_{i}^{D H \text { store capacity }} * E^{\text {DH store } \min S O C}$

$\forall \mathrm{i} \in$ building nodes, $\mathrm{t}$

$$
\begin{gathered}
E_{i, t+1}^{D H} \text { store } S O C=E_{i, t}^{D H} \text { store } S O C * n_{D H} \text { store standing loss }+Q_{i, t}^{D H} \text { store } * n_{D H \text { store charging eff }}- \\
\left(\frac{1}{n_{D H} \text { store discharging eff }}\right) * Q_{i, t}^{D H} \text { store discharge }
\end{gathered}
$$


$\forall \mathrm{i} \in$ building nodes, $\mathrm{t}$

$Q_{i, t}^{D H \text { store charge }} \leq E_{i}^{\text {DH store capacity }} * r_{\mathrm{max}_{-} \text {charge }}$

$\forall \mathrm{i} \in$ building nodes, $\mathrm{t}$

$Q_{i, t}^{D H \text { store discharge }} \leq E_{i}^{\text {DH store capacity }} * r_{\text {max }_{\text {discharge }}}$

$\forall \mathrm{i} \in$ building nodes, $\mathrm{t}$

$E_{i, t}^{D H}$ store $S O C=E_{i, t}^{D H}$ store $S O C$

$\forall \mathrm{i} \in$ building nodes, $\mathrm{t} \in$ first and last time step

$Q_{i, t}^{\text {DH store discharge }} \geq D H W$ load $_{i, t}$

$\forall \mathrm{i} \in$ building nodes, $\mathrm{t}$

where,

$E_{i, t}^{D H}$ store ${ }^{S O C}:$ State of charge of heat storage at $55^{\circ} \mathrm{C}[\mathrm{kW}]$

$E_{i}^{\text {DH store capacity }}:$ Capacity of installed heat storage at $55^{\circ} \mathrm{C}[\mathrm{kW}]$

$n_{D H \text { store standing loss }}$ : Standing losses for heat storage at $55^{\circ} \mathrm{C}[\%$ of capacity]

$n_{D H}$ store charging eff : Charging efficiency of heat storage at $55^{\circ} \mathrm{C}$ [\% of capacity]

$n_{D H}$ store discharging eff : Discharging efficiency of heat storage at $55^{\circ} \mathrm{C}[\%$ of capacity]

$Q_{i, t}^{D H}$ store charge $:$ Heat storage at $55^{\circ} \mathrm{C}$ charging energy $\left[\mathrm{kWh}_{\mathrm{th}}\right]$

$Q_{i, t}^{D H}$ store discharge $:$ Heat storage at $55^{\circ} \mathrm{C}$ discharging energy $\left[\mathrm{kWh}_{\mathrm{th}}\right]$

$r_{\max \text { charge }}$ : Maximum charging rate of the heat storage at $55^{\circ} \mathrm{C}$ [\% of capacity]

$r_{\max \text { discharge }}:$ Maximum discharging rate of the heat storage at $55^{\circ} \mathrm{C}$ [\% of capacity]

$E^{D H}$ store min $S O C$ : Minimum state of charge for heat storage at at $55^{\circ} \mathrm{C}[\%$ of capacity]

The heat produced by the heat pumps can then be stored in the respective heat storage tanks before final consumption. Thus equation 7 and 8 are modified to equation 55 and 56 respectively.

$\operatorname{COP}_{i}^{H P}=\frac{Q_{i, t}^{\text {SH store charge }}+Q_{i, t}^{D H} \text { store charge }}{P_{i, t}^{H P \text { elec }}}$

$\forall \mathrm{i} \in$ building nodes, $\mathrm{t}$

$P_{i, t}^{H P}$ elec $+P_{i, t}^{H P}$ heat $=Q_{i, t}^{S H \text { store charge }}+Q_{i, t}^{D H \text { store charge }}$ 
$\forall \mathrm{i} \in$ building nodes, $\mathrm{t}$ 
Appendix A2

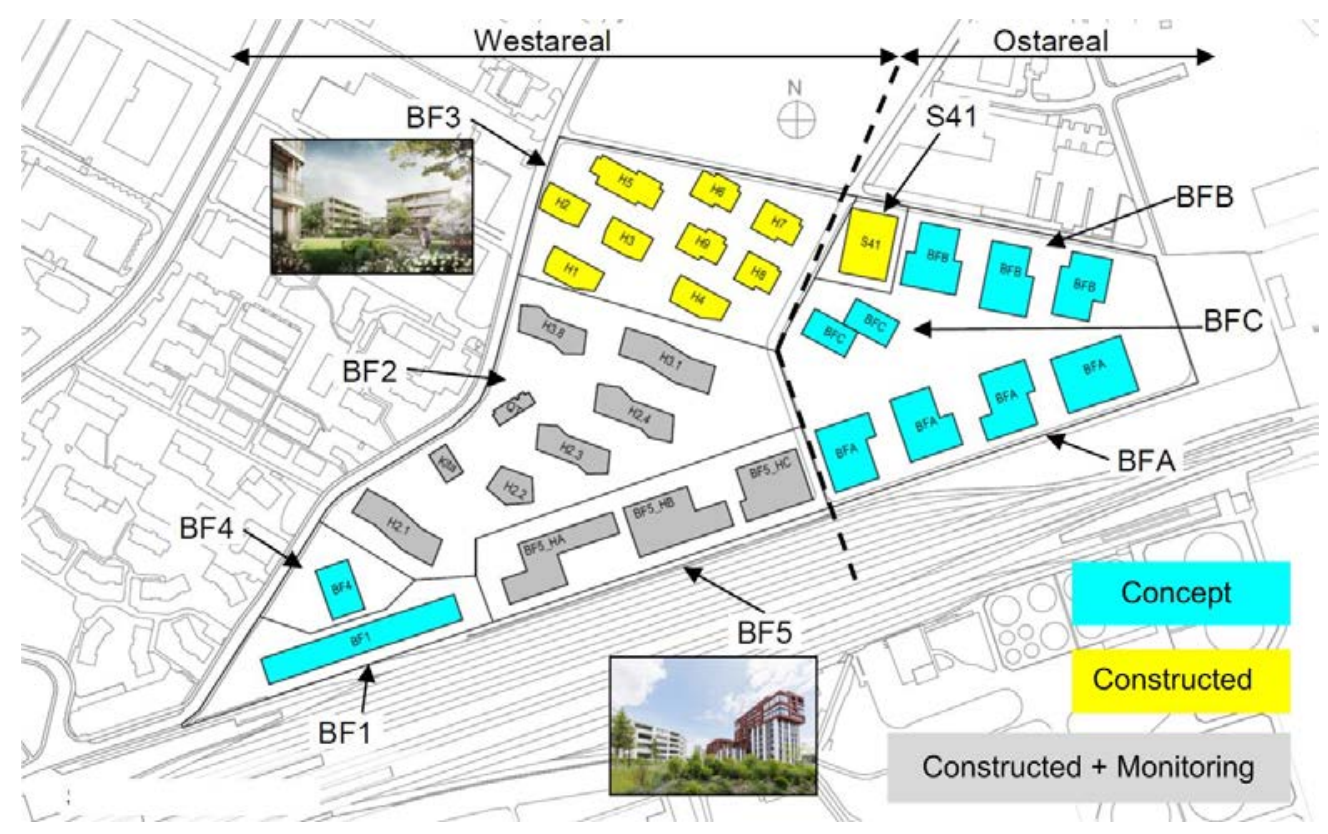

Figure A1. Suurstoffi district and the different building sites.

Table A1. Efficiency, costs and capacities used as an input in the model.

Technology Efficiency/COP

Total capacity

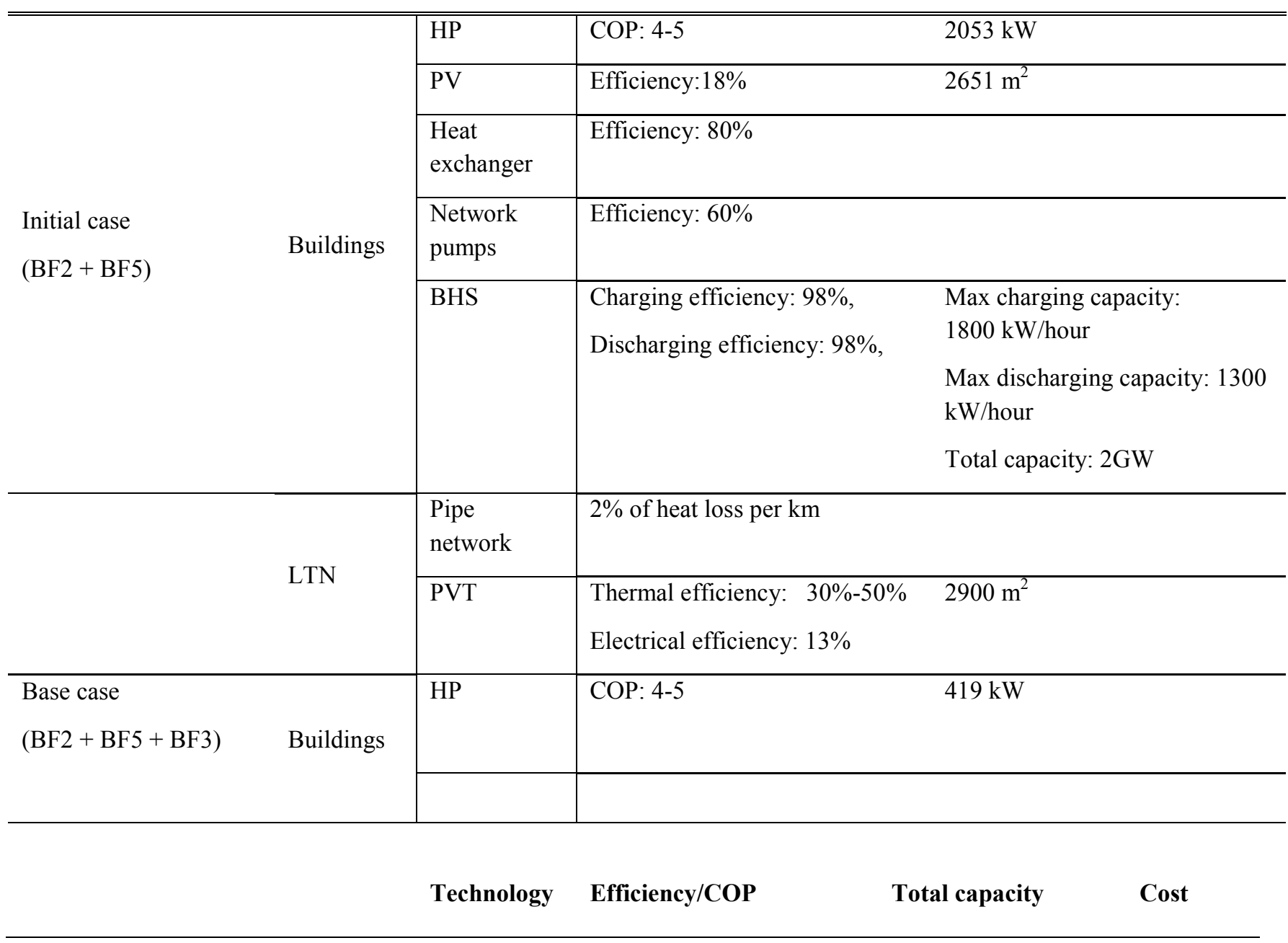




\begin{tabular}{|c|c|c|c|c|c|}
\hline $\begin{array}{l}\text { Scenario } \\
\text { Heat storage }\end{array}$ & Buildings & $\begin{array}{l}\text { Building } \\
\text { storage tank }\end{array}$ & $\begin{array}{l}\text { Charging efficiency: } 92 \% \\
\text { Discharging efficiency: } \\
92 \% \\
\text { Standing loss: } 1 \% \text { per hour }\end{array}$ & $\begin{array}{l}\text { Max charging and } \\
\text { discharging rate: } 85 \% \\
\text { of total capacity } \\
1000 \mathrm{lt}(100-150 \mathrm{~kW}) \\
\text { per building } \\
\text { Min SOC: } 10 \%\end{array}$ & \\
\hline $\begin{array}{l}\text { Scenario } \\
\text { Battery }\end{array}$ & LTN & Battery & $\begin{array}{l}\text { Charging efficiency: } 90 \% \\
\text { Discharging efficiency: } \\
90 \% \\
\text { Standing loss: } 1 \% \text { per hour }\end{array}$ & $\begin{array}{l}\text { Max. charging and } \\
\text { discharging rate: } 30 \% \\
\text { of total capacity } \\
\text { Min SOC: } 20 \%\end{array}$ & $\begin{array}{l}1200 \\
\mathrm{CHF} / \mathrm{kWh}\end{array}$ \\
\hline
\end{tabular}

Additional assumptions include the carbon factor of electricity imported from the grid $(0.038$ $\left.\mathrm{kg} \mathrm{CO}_{2} / \mathrm{kWh}\right)$, the cost of electricity purchased from grid $(0.18 \mathrm{CHF} / \mathrm{kWh})$, the cost of electricity sold to grid $(0 \mathrm{CHF} / \mathrm{kWh})$ and the project lifetime of 20 years.

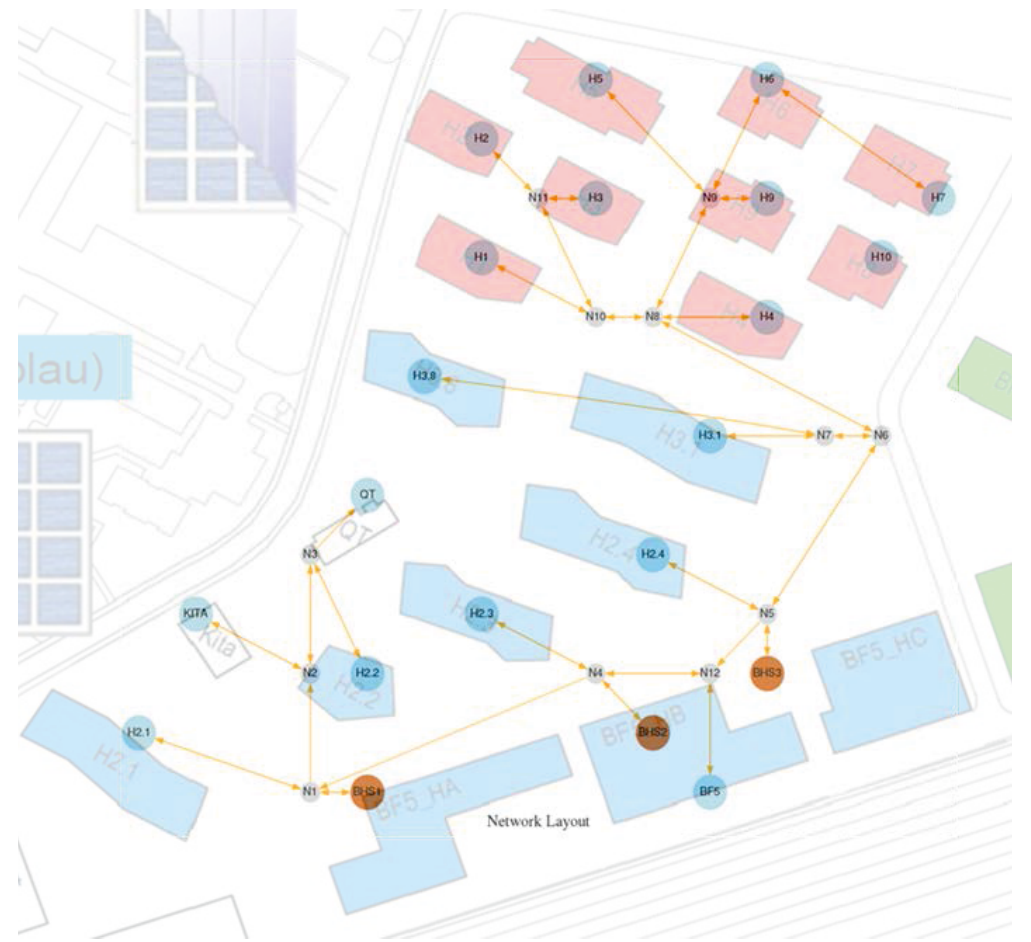

Figure A2. Suurstoffi district with nodes and depiction of network: blue circles depict building nodes; grey circles depict routing nodes; and red circles the borehole entry points. Yellow lines depict the low temperature network. 
Space Heating demand

- BF2 - BF5

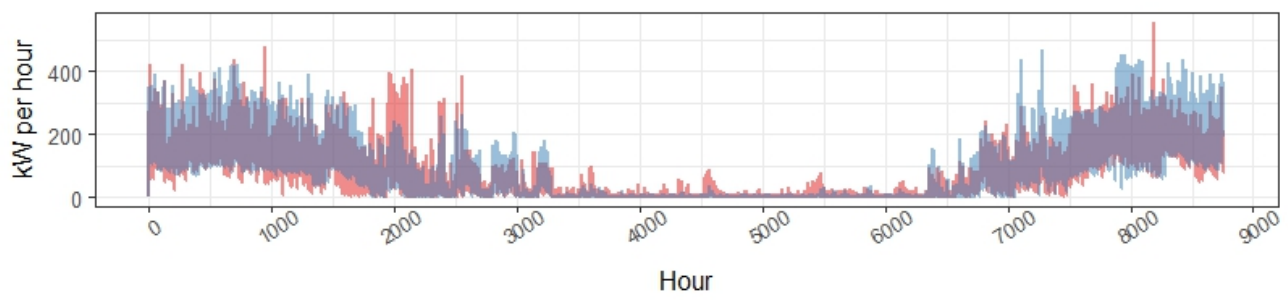

Hot water demand

$-\mathrm{BF} 2-\mathrm{BF} 5$

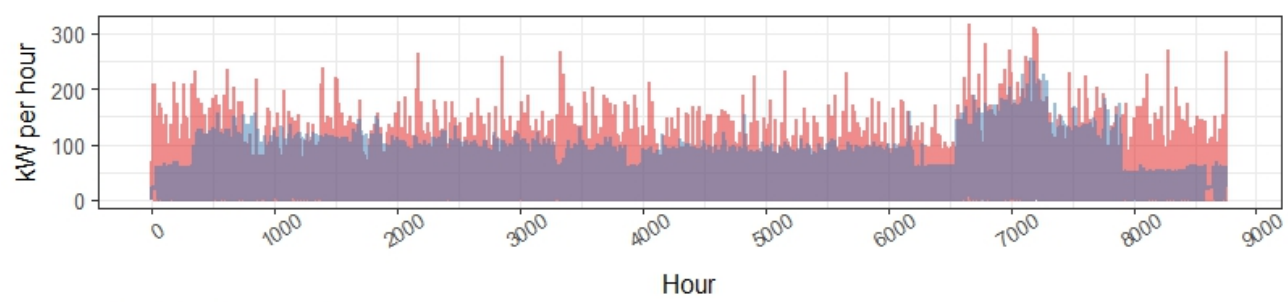

Cooling demand

- BF2 - BF5

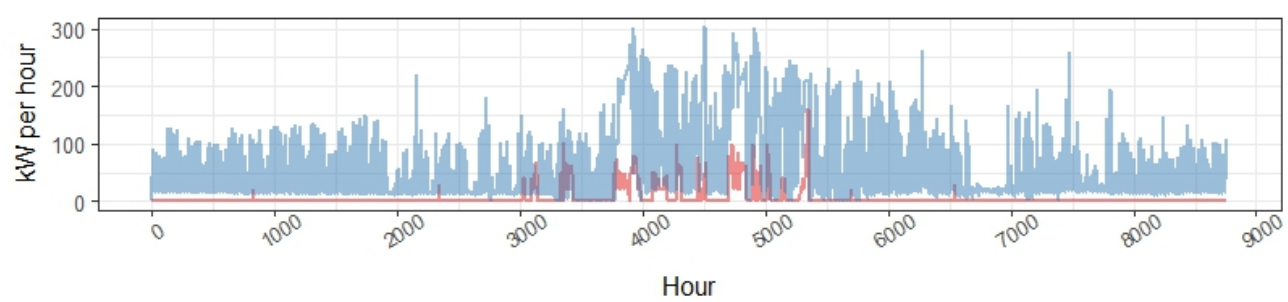

Figure A3. Space heating, hot water and cooling demand profiles used as an input to the model (the BF2 curve shown here is the sum of 8 individual building demand curves used in the model). 

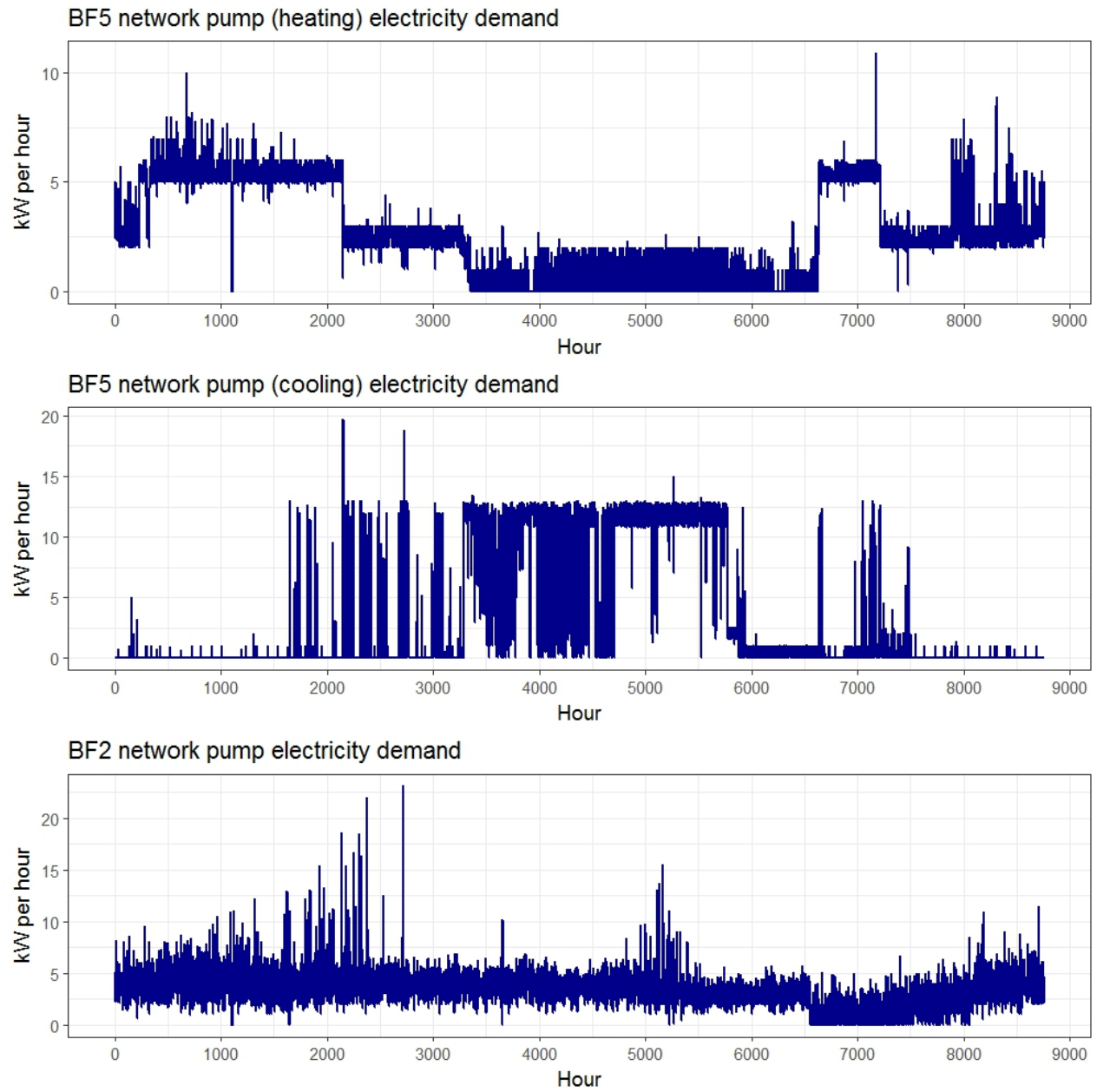

Figure A4. Network pump electricity demands (data from monitoring). Network pump demands for 8 buildings in BF2 are summed. No data was available on BF2 network pumps used for free-cooling. 
Table A2. Summary of district heating and cooling demands (expanded table).

\begin{tabular}{|c|c|c|c|c|c|c|c|c|c|}
\hline & $\begin{array}{r}\text { Space heating } \\
{[\mathrm{MWh} / \mathrm{y}]}\end{array}$ & $\begin{array}{r}\text { Space heating } \\
{\left[\mathrm{kWh} / \mathrm{y} / \mathrm{m}^{2}\right]}\end{array}$ & $\begin{array}{l}\text { Hot water } \\
{[\mathrm{MWh} / \mathrm{y}]}\end{array}$ & $\begin{array}{r}\text { Hot water } \\
{\left[\mathrm{kWh} / \mathrm{y} / \mathrm{m}^{2}\right]}\end{array}$ & $\begin{array}{r}\text { Cooling } \\
{[\mathrm{MWh} / \mathrm{y}]}\end{array}$ & $\begin{array}{r}\text { Cooling } \\
{\left[\mathrm{kWh} / \mathrm{y} / \mathrm{m}^{2}\right]}\end{array}$ & $\begin{array}{r}\text { Total heating } \\
\text { demand }[\mathrm{MWh} / \mathrm{y}]\end{array}$ & $\begin{array}{r}\text { Total Cooling } \\
\text { demand [MWh/y] }\end{array}$ & $\begin{array}{r}\text { Installed HP } \\
\text { capacity [kW] }\end{array}$ \\
\hline BF2 & 629 & 36.5 & 283 & 19.2 & 56 & 2.2 & 912 & 56 & 974 \\
\hline BF5 & 797 & 33.6 & 380 & 19.4 & 533 & 18.8 & 1177 & 533 & 1021 \\
\hline $\mathrm{BF} 2+\mathrm{BF} 5$ [measured] & 1426 & & 663 & & 589 & & 2089 & 589 & \\
\hline BF3 & 507 & 40.7 & 213 & 20.9 & 64 & 4 & 720 & 64 & \\
\hline $\mathrm{BF} 2+\mathrm{BF} 5+\mathrm{BF} 3$ & 1933 & & 876 & & 653 & & 2809 & 653 & \\
\hline Whole site [estimate] & 5624 & & 1828 & & 2117 & & 7452 & 2117 & \\
\hline
\end{tabular}

